\title{
QUEEN'S
UNIVERSITY
BELFAST
}

\section{FhCaBP3: A Fasciola hepatica calcium binding protein with EF-hand and dynein light chain domains}

\author{
Banford, S., Drysdale, O., Hoey, E. M., Trudgett, A., \& Timson, D. J. (2013). FhCaBP3: A Fasciola hepatica \\ calcium binding protein with EF-hand and dynein light chain domains. Biochimie, 95(4), 751-758. \\ https://doi.org/10.1016/j.biochi.2012.10.027
}

\section{Published in:}

Biochimie

\section{Document Version:}

Peer reviewed version

Queen's University Belfast - Research Portal:

Link to publication record in Queen's University Belfast Research Portal

\section{Publisher rights}

NOTICE: this is the author's version of a work that was accepted for publication in Biochimie. Changes resulting from the publishing process, such as peer review, editing, corrections, structural formatting, and other quality control mechanisms may not be reflected in this document. Changes may have been made to this work since it was submitted for publication. A definitive version was subsequently published in Biochimie, [VOL 95, ISSUE 4, 2013]

\section{General rights}

Copyright for the publications made accessible via the Queen's University Belfast Research Portal is retained by the author(s) and / or other copyright owners and it is a condition of accessing these publications that users recognise and abide by the legal requirements associated with these rights.

\section{Take down policy}

The Research Portal is Queen's institutional repository that provides access to Queen's research output. Every effort has been made to ensure that content in the Research Portal does not infringe any person's rights, or applicable UK laws. If you discover content in the Research Portal that you believe breaches copyright or violates any law, please contact openaccess@qub.ac.uk. 


\section{Accepted Manuscript}

FhCaBP3: A Fasciola hepatica calcium binding protein with EF-hand and dynein light chain domains

Samantha Banford, Orla Drysdale, Elizabeth M. Hoey, Alan Trudgett, David J. Timson

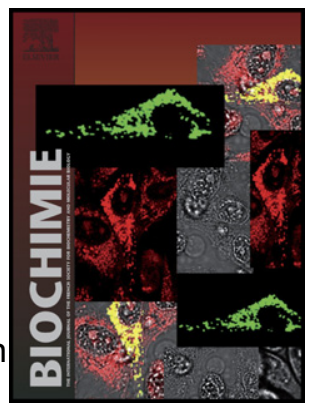

PII:

S0300-9084(12)00443-9

DOI:

10.1016/j.biochi.2012.10.027

Reference: $\quad \mathrm{BIOCHI} 4065$

To appear in: Biochimie

Received Date: 30 August 2012

Accepted Date: 31 October 2012

Please cite this article as: S. Banford, O. Drysdale, E.M Hoey, A. Trudgett, D.J Timson, FhCaBP3: A Fasciola hepatica calcium binding protein with EF-hand and dynein light chain domains, Biochimie (2012), doi: 10.1016/j.biochi.2012.10.027.

This is a PDF file of an unedited manuscript that has been accepted for publication. As a service to our customers we are providing this early version of the manuscript. The manuscript will undergo copyediting, typesetting, and review of the resulting proof before it is published in its final form. Please note that during the production process errors may be discovered which could affect the content, and all legal disclaimers that apply to the journal pertain. 

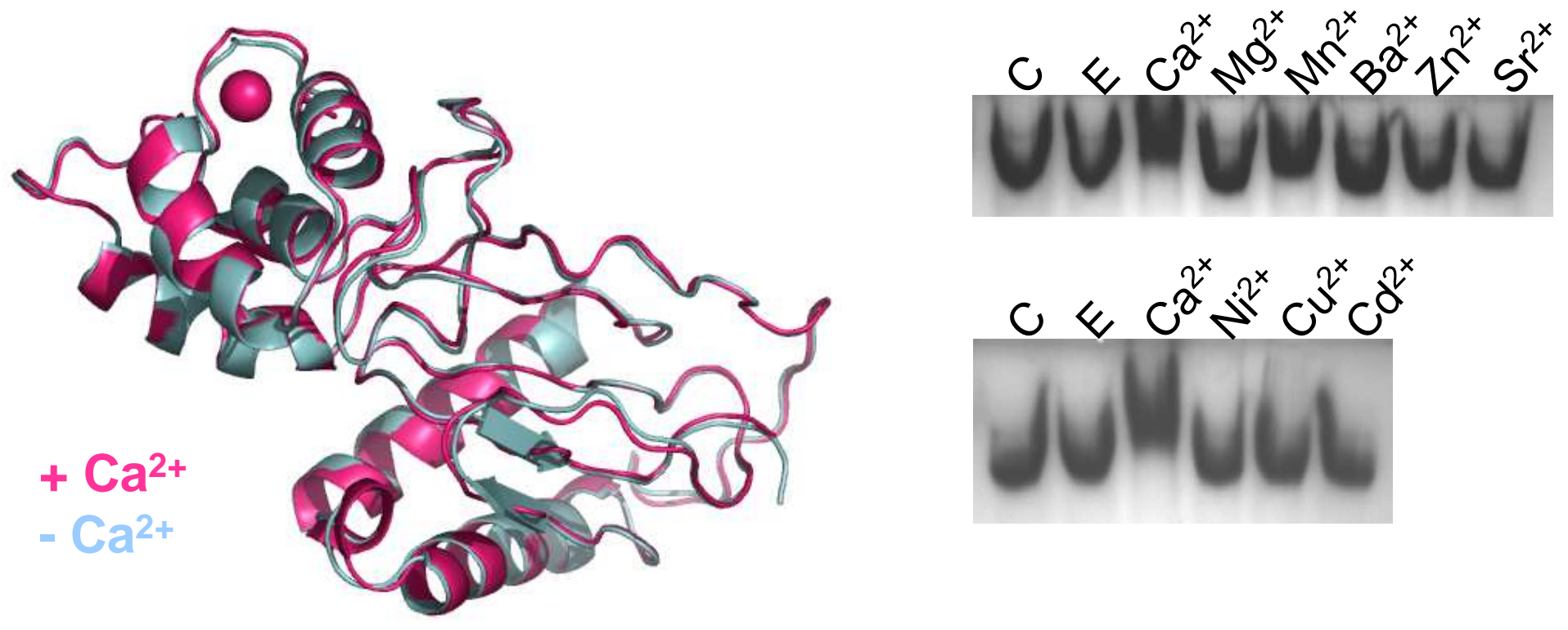
FhCaBP3: a Fasciola hepatica calcium binding protein with EFhand and dynein light chain domains

Samantha Banford, Orla Drysdale, Elizabeth M Hoey, Alan Trudgett and David J Timson

\section{Highlights}

- FhCaBP3 contains two EF-hand motifs and a dynein light chain-like domain

- Modelling predicts that calcium ion binding disrupts $\beta$-sheets in the DLC domain

- $\quad$ FhCaBP3 binds $\mathrm{Ca}^{2+}$ and $\mathrm{Mn}^{2+}$ ions, but not $\mathrm{Mg}^{2+}, \mathrm{Ba}^{2+}, \mathrm{Sr}^{2+}, \mathrm{Zn}^{2+}, \mathrm{Cd}^{2+}, \mathrm{Cu}^{2+}$, $\mathrm{Ni}^{2+}$

- FhCaBP dimerises, but calcium ions reduce the amount of dimerisation

- FhCaBP3 binds a range of calmodulin antagonists 
FhCaBP3: a Fasciola hepatica calcium binding protein with EF-

hand and dynein light chain domains

Samantha Banford, Orla Drysdale, Elizabeth M Hoey, Alan Trudgett and David J Timson*

School of Biological Sciences, Queen's University Belfast, Medical Biology Centre, 97 Lisburn Road, Belfast, BT9 7BL. UK.

* Corresponding author

Telephone: $\quad+44(0) 2890975875$

Fax: $\quad+44(0) 2890975877$

Email: $\quad$ d.timson@qub.ac.uk 


\section{Abstract}

A DNA sequence encoding a protein with predicted EF-hand and dynein light chain binding domains was identified in a Fasciola hepatica EST library. Sequence analysis of the encoded protein revealed that the most similar known protein was the Fasciola gigantica protein $\mathrm{FgCaBP} 3$ and so this newly identified protein was named FhCaBP3. Molecular modelling of FhCaBP3 predicted a highly flexible N-terminal region, followed by a domain containing two EF-hand motifs the second of which is likely to be a functioning divalent ion binding site. The $\mathrm{C}$-terminal domain of the protein contains a dynein light chain like region. Interestingly, molecular modelling predicts that calcium ion binding to the $\mathrm{N}$-terminal domain destabilises the $\beta$-sheet structure of the C-terminal domain. FhCaBP3 can be expressed in, and purified from, Escherichia coli. The recombinant protein dimerises and the absence of calcium ions appeared to promote dimerisation. Native gel shift assays demonstrated that the protein bound to calcium and manganese ions, but not to magnesium, barium, zinc, strontium, nickel, copper or cadmium ions. FhCaBP3 interacted with the calmodulin antagonists trifluoperazine, $\mathrm{N}$-(6-aminohexyl)-5-chloro-1-naphthalenesulfonamide and chlorpromazine as well as the myosin regulatory light chain-binding drug praziquantel. Despite sequence and structural similarities to other members of the same protein family from $F$. hepatica, FhCaBP3 has different biochemical properties to the other well characterised family members, FH22 and FhCaBP4. This suggests that each member of this trematode calcium-binding family has discrete functional roles within the organism.

Keywords: EF-hand; trematode, calcium binding protein; liver fluke; DLC 


\section{Introduction}

Calcium homeostasis is required in all living cells. Consequently, elaborate molecular systems have evolved to control the flow of calcium ions in and out of cells. Changes in calcium ion concentrations in cells also act as cellular signals and there are a number of proteins which sense these changes and transmit information to signalling pathways [1]. The best characterised of these is calmodulin, an approximately $17 \mathrm{kDa}$ protein which has two globular heads joined by an $\alpha$-helical linker. Each globular head contains two EF-hand, calcium ion binding domains. In each EF-hand, the ion is coordinated by a combination of six functional groups from the side chains and backbone of the protein [2-5]. Binding to calcium ions by the EF-hands induces a conformational change which results in the greater exposure of hydrophobic residues on the surface of the protein $[6,7]$. These hydrophobic residues are important in interacting with some partner proteins and also with some drugs [6-10]. A number of calmodulin and calmodulin-like proteins have been characterised in trematodes. These include two calmodulins from the blood fluke Schistosoma mansoni (SmCaM1 and SmCaM2) which show very high protein sequence similarity (>97\%) to the human protein [11]. In the common liver fluke, Fasciola hepatica, there are at least three calmodulin-like proteins. One, FhCaM1, an orthologue of SmCaM1, differs from human calmodulin by only two amino acid residues $[12,13]$. The other two, FhCaM2 and FhCaM3, are more different at the sequence level (67\% and 51\% similarity respectively); however they are predicted to have similar overall structures to mammalian calmodulins $[12,13]$.

EF-hands are not only found in calmodulin and related proteins. In trematodes there are at least two families of EF-hand containing proteins which are not present in their 
mammalian hosts. The first family is one containing small (approximately $8 \mathrm{kDa}$ ) proteins with one EF-hand and includes FH8 from F. hepatica, Sm8 from S. mansoni and $\mathrm{SjCa} 8$ from Schistosoma japonicum [14-16]. In the case of FH8, the calcium binding affinity has been shown to be low $\left(\mathrm{K}_{\mathrm{d}} \sim 10^{-4} \mathrm{M}\right)$ [16]. The second family consists of proteins which combine two EF-hand domains with a dynein light chain (DLC) domain. The functions of these proteins have not been determined although some have been localised to the fluke's tegument $[17,18]$. Indeed, many species express several different proteins from this family suggesting either a requirement for redundancy or different functions for each family member. Examples of these proteins include, the S. mansoni proteins Sm22.6 (SmTAL1), Sm21.7 (SmTAL3), Sm20.8 (SmTAL3) and Sm21.6 (SmTAL8), the Schistosoma japonicum protein Sj22.6, Schistosoma haematobium Sh22.6, the C. sinensus proteins CsTP31.8 and CsTegu21.6 and the Opisthorchis viverrini protein OvCaBP [19-27]. Recently, a family of related proteins in S. mansoni (SmTAL4 to SmTAL13) were identified by bioinformatics and partially characterised [28]. In Fasciola gigantica, four proteins from the family have been characterised thus far: $\mathrm{FgCaBP} 1, \mathrm{FgCaBP} 2, \mathrm{FgCaBP} 3$ and FgCaBP4. These proteins all bind calcium ions and FgCaBP1 is recognised by immune serum from infected rabbits, suggesting that the protein is secreted $[17,18]$. In the closely related liver fluke, F. hepatica, two family members have been characterised to date. $\mathrm{FH} 22$ is the equivalent of $\mathrm{FgCaBP} 1$, undergoes calciumdependent conformational changes and is secreted from the fluke [29].

Interest in this group of calcium binding proteins which contain EF-hand and DLClike domains arises from their ability to induce by $\operatorname{IgG}$ and $\mathrm{IgE}$-mediated immune responses in their hosts [23, 30-32] and from their potential as novel drug targets. The 
central importance of calcium homeostasis and calcium-mediated cellular signalling means that disruption of these networks is likely to result in deleterious effects on the fluke. This family of proteins are particularly attractive as possible drug targets since they are unique to trematodes and thus molecules which antagonise their actions are less likely to interact with host molecules. However, our current lack of detailed biochemical data prevents a full assessment of their potential as drug targets. The need for novel therapeutics to control fasciolosis is urgent as resistance to the current drug of choice, triclabendazole, has now been reported worldwide [33-39]. Recently, we biochemically characterised $\mathrm{FhCaBP} 4$ (which has an identical protein sequence to FgCaBP4) and demonstrated that it binds calcium and some other divalent cations, undergoes a calcium-dependent conformational change which results in a more hydrophobic surface and dimerisation and that it interacts with the calmodulin antagonist W7 [40]. Here, we describe the biochemical characterisation of the third F. hepatica member of this family. This protein is homologuous to $\mathrm{FgCaBP} 3$ and thus we have named it $\mathrm{FhCaBP} 3$.

\section{Materials and Methods}

\subsection{Cloning, expression and purification of FhCaBP3}

The coding sequence for FhCaBP3 was PCR-amplified using clone Fhep26e01 from a F. hepatica EST library as a template (available at: ftp://ftp.sanger.ac.uk/pub4/pathogens/Fasciola/hepatica/ESTs/) [41]. The amplicon was cloned into the Escherichia coli expression vector pET46 Ek/LIC (Merck, Nottingham, UK) according to the manufacturer's instructions. (Note that this vector introduces bases coding for the amino acid sequence MAHHHHHHVDDDDK at the 
$5^{\prime}$ end of the coding sequence.) Correct insertion into the vector was verified by PCR and by DNA sequencing (GATC, London, UK) of the insert.

The expression vector was used to transform competent E. coli HMS174(DE3) and colonies resulting from this transformation were used to inoculate cultures $(5 \mathrm{ml}$ of Luria-Bertani medium (LB) supplemented with $100 \mu \mathrm{g} \cdot \mathrm{ml}^{-1}$ ampicillin) which were grown at $37^{\circ} \mathrm{C}$ overnight with shaking. Each culture was then diluted into 11 of LB (supplemented with $100 \mu \mathrm{g} \cdot \mathrm{ml}^{-1}$ ampicillin), grown until A600 reached 0.6 to 1.0 (typically 3-4h), induced with $1 \mathrm{mM}$ IPTG and then grown for further $2 \mathrm{~h}$. After this time, the cells were collected by centrifugation (4200 $\mathrm{g}$ for $15 \mathrm{~min}$ ), resuspended in approximately $20 \mathrm{ml}$ of buffer R (50 mM Hepes-OH, pH 7.5, $150 \mathrm{ml}$ sodium chloride, $10 \%(\mathrm{v} / \mathrm{v})$ glycerol) and frozen at $-80{ }^{\circ} \mathrm{C}$.

These cell suspensions were thawed and the cells disrupted by sonication on ice (three times $100 \mathrm{~W}$ pulses of $30 \mathrm{~s}$ duration with 30-60 s gaps inbetween for cooling). Solid debris was removed immediately by centrifugation $\left(22,000 \mathrm{~g}\right.$ for $15 \mathrm{~min}$ at $\left.4{ }^{\circ} \mathrm{C}\right)$ and the supernatant applied to a nickel-agarose column ( $1 \mathrm{ml}$, His-Select,Sigma, Poole, UK) which had been pre-equilibrated in buffer A (as buffer R, except $500 \mathrm{mM}$ sodium chloride). The supernatant was allowed to pass through under gravity and the column was then washed with $20 \mathrm{ml}$ buffer A. FhCaBP3 was eluted with three $2 \mathrm{ml}$ washes with buffer B (buffer A supplemented with $250 \mathrm{mM}$ imidazole) and its purity verified by SDS-PAGE. Protein containing fractions were dialysed overnight at $4{ }^{\circ} \mathrm{C}$ against buffer D (buffer R supplemented with 1 mM DTT). The concentration of FhCaBP3 was determined by the method of Bradford [42] using BSA as a control. The protein solution was divided into aliquots $(50-100 \mu \mathrm{l})$ and stored at $-80{ }^{\circ} \mathrm{C}$ until required. 


\subsection{Bioinformatics and Molecular Modelling}

Multiple sequence alignments were constructed using ClustalW [43, 44] and an unweighted pair group method with arithmetic mean (UPGMA) tree was generated using MEGA 5.05 [45].

A molecular model of FhCaBP3 was constructed by using Phyre2

((http://www.sbg.bio.ic.ac.uk/phyre2 [46]) in the "intensive" mode. This model was then minimised and computationally solvated using YASARA

(http://www.yasara.org/minimizationserver.htm [47]). Potential ligand binding sites in this model were identified using 3dligandsite

(http://www.sbg.bio.ic.ac.uk/3dligandsite [48]). A calcium ion was modelled into the structure using Reps1 EH domain (PDB ID: 1FI6 [49]) as a template and the resulting structure re-minimised using YASARA. The final, calcium bound and calcium free, minimised models are provided as supplementary data to this paper.

\subsection{Native gel electrophoresis}

FhCaBP3 $(90 \mu \mathrm{M})$ was mixed with $1 \mathrm{mM}$ EGTA and $1 \mathrm{mM}$ DTT and the mixture supplemented with divalent metal ions $(2 \mathrm{mM})$ as required in a total volume of $10 \mu \mathrm{l}$. Note that EGTA was routinely included in these mixtures to remove any calcium ions which had associated with FhCaBP3 during the expression and purification process. (This has been previously observed with other $F$. hepatica calcium binding proteins $[13,40])$. Mixtures were incubated at room temperature for $5 \mathrm{~min}$ and then $10 \mu \mathrm{l}$ native gel loading buffer (120 mM Tris pH 6.8, 20\% (v/v) glycerol, 5\% (w/v) bromophenol blue, $1 \%(w / v)$ DTT) was added. Electrophoresis was carried out using 
$10 \%$ polyacrylamide gels ( $\mathrm{pH} \mathrm{8.8),} \mathrm{with} \mathrm{a} \mathrm{running} \mathrm{buffer} \mathrm{of} 25 \mathrm{mM}$ Tris- $\mathrm{HCl}, 250$ $\mathrm{mM}$ glycine, $\mathrm{pH} 8.8$ at $20 \mathrm{~mA}$ (constant current) for $40 \mathrm{~min}$. Gels were stained with Coomassie blue (dissolved in $45 \%$ (v/v) ethanol, $10 \%$ (v/v) glacial acetic acid) and destained in $0.75 \%(\mathrm{v} / \mathrm{v})$ glacial acetic acid/ $0.5 \%(\mathrm{v} / \mathrm{v})$ ethanol.

\subsection{Fluorescence measurements}

Intrinsic fluorescence spectra of FhCaBP3 $(2 \mu \mathrm{M}$; supplemented with $1 \mathrm{mM}$ DTT in a total volume of $150 \mu \mathrm{l}$ ) were recorded from 310 to $400 \mathrm{~nm}$ using a Spectra Max Gemini XS fluorescence plate-reader and SOFTmax PRO software in a FluoroNunc ${ }^{\mathrm{TM}}$ black 96-well plate using an excitation wavelength of $280 \mathrm{~nm}$. For 8anilinonaphthalene-1-sulphonate (ANS) displacement assays, FhCaBP3 $(9 \mu \mathrm{M})$ was incubated for $1 \mathrm{~h}$ at $37^{\circ} \mathrm{C}$ with either $2 \mathrm{mM} \mathrm{CaCl}_{2} / 1 \mathrm{mM}$ EGTA or $1 \mathrm{mM}$ EGTA in the presence of $20 \mu \mathrm{M}$ ANS in a total volume of $150 \mu 1$. The negative control contained 10 mM HEPES pH 8.8 and $20 \mu$ M ANS. The fluorescence spectrum (440 $\mathrm{nm}$ to $510 \mathrm{~nm}$; excitation wavelength $350 \mathrm{~nm}$ ) was then recorded.

\subsection{Crosslinking}

FhCaBP3 $(30 \mu \mathrm{M})$ was incubated with bis(sulfosuccinimidyl) suberate $\left(\mathrm{BS}^{3}, 80\right.$ or $800 \mu \mathrm{M})$ in the presence of either $1 \mathrm{mM}$ EGTA or $1 \mathrm{mM}$ EGTA/2 mM calcium chloride for $30 \mathrm{~min}$ at $37^{\circ} \mathrm{C}$. Products were then analysed by $10 \%$ SDS-PAGE. Crosslinking with 1-Ethyl-3-(3-dimethylaminopropyl)carbodiimide hydrochloride (EDC) was carried out as previously described [40].

\subsection{Analytical gel filtration}


FhCaBP3 (200 $\mu$ of a $380 \mu \mathrm{M}$ solution) in the presence of either $2 \mathrm{mM}$ calcium chloride or 2 mM EGTA was chromatographed on a Sephacryl S-300 (Pharmacia) column (total volume, $\mathrm{V}_{\mathrm{t}}=55 \mathrm{ml}$; void volume, $\mathrm{V}_{0}=17.5 \mathrm{ml}$ ) at a flow rate of $1 \mathrm{ml}^{\mathrm{min}} \mathrm{min}^{-}$

1. The column was equilibrated and developed in buffer G $(50 \mathrm{mM}$ Tris- $\mathrm{HCl}, 17 \mathrm{mM}$ Tris base, $150 \mathrm{mM}$ sodium chloride, $\mathrm{pH} 7.4$ [50]) supplemented with either $2 \mathrm{mM}$ calcium chloride or $2 \mathrm{mM}$ EGTA as appropriate. Fractions (1 ml) were collected and analysed for protein content by measuring the absorbance at $280 \mathrm{~nm}$. Standard proteins (albumin, $67 \mathrm{kDa}$ and ribonuclease $\mathrm{A}, 13.7 \mathrm{kDa}$ ) were used to calibrate the column. Their elution volumes $\left(\mathrm{V}_{\mathrm{e}}\right)$ were used to calculate $\mathrm{K}_{\mathrm{av}}$ according to the equation:

$K_{a v}=\frac{V_{e}-V_{0}}{V_{t}-V_{e}}$

Molecular masses were estimated by making use of the inverse, linear correlation between $\mathrm{K}_{\mathrm{av}}$ and the logarithm of the molecular mass [51].

\subsection{Limited proteolysis}

FhCaBP3 $(40 \mu \mathrm{M})$ was incubated in the presence of drug $(250 \mu \mathrm{M})$ and $2 \mathrm{mM}$ calcium chloride for $5 \mathrm{~min}$ at $37^{\circ} \mathrm{C}$. After this time chymotrypsin $(200 \mathrm{nM})$ was added and the mixture incubated for $30 \mathrm{~min}$ at $37^{\circ} \mathrm{C}$. Products were resolved on $15 \%$ SDS-PAGE.

\section{Results}

\subsection{FhCaBP3: sequence analysis and predicted structure}

The coding sequence of $\mathrm{FhCaBP} 3$ codes for a 210 amino acid residue protein of molecular mass approximately $26 \mathrm{kDa}$ and an estimated isoelectric point of 6.4. The 
N-terminal part (residues 1-98) of the protein is predicted to form two EF-hand domains and the C-terminal part (residues 118-210) a DLC-like domain (figure 1a). The sequence has been submitted to the GenBank database with the accession number JX070093. A BLAST search revealed that the most similar known protein is the $F$. gigantica protein $\mathrm{FgCaBP} 3$ from which it differs by only two amino acid residues. A BLAST search revealed that the most similar known protein is the $F$. gigantica protein $\mathrm{FgCaBP} 3$ from which it differs by only two amino acid residues. An UPGAMA phylogenetic analysis shows that the sequence clusters with $\mathrm{FgCaBP}$, $\mathrm{FH} 22$ and $\mathrm{FgCaBP} 1$ (figure 1b).

A molecular model of the protein predicted that it is organised into two domains joined by a flexible linker (figure $2 \mathrm{a}$ ). The N-terminal domain contains two EF-hand motifs. Prediction of the ligand binding properties of the protein, using 3DLigandSite predicted that the second of these EF-hands can be occupied by a calcium ion. The two highest matches used for modelling of the EF-hand domain, the EF-hand domain of human RASEF (PDB ID: 2PMY, unpublished) and the Reps1 EH domain (PDB ID: 1FI6 [49]) have two and one calcium ions bound respectively. Therefore, a calcium ion was modelled at the second EF-hand only (figure 2b). In EF-hands, six residues contribute to the coordination of the ion. These are designated the $\mathrm{X}, \mathrm{Y}, \mathrm{Z},-\mathrm{Y},-\mathrm{X}$ and $-\mathrm{Z}$ residues and analysis of EF-hand proteins has identified consensus residues at these positions [52]. In both EF-hands in FhCaBP3, the consensus is largely observed, with the greatest deviation at the fourth coordinating position (-Y) which is most commonly a threonine (figure 2c,d). In the first EF-hand this residue is a serine (which is rarely seen at this position in EF-hands) and in the second EF-hand it is a lysine, which while 
observed occasionally in EF-hands, introduces a positive charge into the motif. However, the modelled structure shows that the positively charged lysine side chain is directed away from the calcium ion (figure $2 \mathrm{~d}$ ).

Dynein light chains are typically rich in $\beta$-sheets $[53,54]$. Interestingly, following minimisation of the modelled structure of FhCaBP3 in the absence of calcium ions, two of the four $\beta$-strands seen in dynein light chains were modelled as random coil structures (figure $2 \mathrm{a}$ ). In the presence of a modelled calcium ion, all four $\beta$-strands were converted to a random coil structure (figure $2 \mathrm{~b}$ ). However, in the presence of a modelled magnesium ion, only two of the strands were converted to random coil, in a similar fashion to the ion-free protein. Modelling a manganese ion into the binding site resulted in complete disruption of two of the $\beta$-sheets and partial disruption of the remaining two (data not shown).

FhCaBP3 and $\mathrm{FgCaBP} 3$ differ from other members of the family in that they have an extended $\mathrm{N}$-terminal region (amino acids 1 to 17 ). In the model, this is predicted to form a random coil and wrap around the C-terminal, DLC-like domain. Estimation of the flexibility of the polypeptide chain predicted that this region is, by far, the most flexible part of the protein suggesting that it can adopt multiple conformations including the one shown in the model (figure 2e).

\subsection{Expression, purification and dimerisation of FhCaBP3}

FhCaBP3 could be expressed in, and purified from E. coli cells. Typical yields were approximately $20 \mathrm{mg}$ protein per litre of bacterial cell culture (figure 3). Interestingly, 
when the protein was resolved by SDS-PAGE a fraction of the protein appeared to run at twice the expected molecular mass. This suggests that some of the protein formed dimers which are resistant to separation by SDS and heat treatment (figure 3). Heat and SDS-resistant oligomerisation has been observed in a number of other proteins, for examples see [55-59]. The intensity of this band was not reduced by supplementation of the loading buffer with additional DTT (2 mM, data not shown).

The ability of FhCaBP3 to form homodimers was further investigated using chemical crosslinking with the reagent $\mathrm{BS}^{3}$. Resolution of the crosslinked products by SDSPAGE revealed a band corresponding to a $\mathrm{FhCaBP} 3$ homodimer in the presence and absence of calcium ions. However, the intensity of this band was greater in the absence of calcium ions (figure 4a). Similar results were seen with the reagent EDC (data not shown). A change in molecular mass was also detected by gel filtration chromatography. The protein eluted at a larger volume in the presence of $2 \mathrm{mM}$ EGTA, than in the presence of $2 \mathrm{mM}$ calcium chloride (figure $4 \mathrm{~b}$ ). The molecular mass of the protein in the presence of calcium ions was estimated by this method to be $21 \mathrm{kDa}$ compared to $38 \mathrm{kDa}$ in their absence; these values are consistent with dimerisation being promoted by the absence of calcium ions. Furthermore, the peak observed in the absence of free calcium ions was much sharper and more symmetrical than the one observed the presence suggesting conformational heterogeneity in the calcium-bound state (figure $4 b$ ).

\subsection{FhCaBP3 binds calcium and other divalent cations}

Ion binding often alters the overall conformation and charge of proteins and thus it can be detected by changes of mobility in native gel electrophoresis. In this 
technique, the mobility of proteins is determined by the charge, hydrodynamic volume and shape of the molecule; all three of these may be affected by the binding of divalent cations. FhCaBP3's electrophoretic mobility was reduced in the presence of calcium ions (figure 5a). Managanese ions were also able to reduce the mobility, demonstrating that the protein can also bind these species. However, no binding to magnesium, barium, zinc, strontium, nickel, copper and cadmium ions was detected (figure 5a).

In many calcium ion binding proteins, including FhCaBP4, calcium ion binding increases the surface hydrophobicity [40]. This change can be detected through increased interaction, and consequent enhanced fluorescence, of the probe 8anilinonaphthalene-1-sulphonate (ANS) [16, 60-62]. However, in the case of FhCaBP3 no such change in ANS fluorescence could be detected (data not shown). Measurement of the intrinsic fluorescence of the protein demonstrated a modest enhancement in the fluorescence intensity in the presence of calcium (figure 5b) providing further evidence for interaction with this ion.

\subsection{FhCaBP3 interacts with calmodulin antagonists}

The ability of FhCaBP3 to interact with calmodulin binding drugs was probed by limited proteolysis and fluorescence spectroscopy. Limited proteolysis with chymotrypsin degrades FhCaBP3 into several fragments (figure 6a, lane -). This digestion pattern is not greatly affected by the presence of $1 \%(\mathrm{v} / \mathrm{v}) \mathrm{DMSO}$, the solvent used for the drugs. The calmodulin antagonists trifluoperazine (TFP) and N(6-aminohexyl)-5-chloro-1-naphthalenesulfonamide (W7) as well as the myosin regulatory light chain binding drug praziquantel (PZQ) all altered the digestion 
pattern; the calmodulin antagonist chlorpromazine (CPZ) did not (figure 6a). The intrinsic fluorescence spectrum of FhCaBP3 was not greatly altered by $1 \%(\mathrm{v} / \mathrm{v})$ DMSO or $250 \mu \mathrm{M}$ PZQ. However, TFP and CPZ both caused a considerable quenching of the fluorescence emission intensity and a modest increase in the wavelength of maximum emission intensity (figure 6b). Note that it was not possible to measure the effects of W7 by this method due to the fluorescence of this compound which overlapped that of the protein.

\section{Discussion}

FhCaBP3 belongs to a family of trematode proteins which contain EF-hand and dynein light chain-like domains. To date, this family appears to be unique to trematodes and thus is of particular interest in understanding the biochemistry of this class of parasitic organisms. Although there is considerable sequence (and thus, most likely, structural) similarity between members of this group of proteins, biochemical differences have been identified.

The other members of the family from $F$. hepatica which have been well characterised at the biochemical level are FH22 and FhCaBP4 [29, 40]. Compared to these, FhCaBP3 has an N-terminal extension which is predicted to be largely unstructured. The function of this region is currently unclear, but intrinsically unstructured regions of proteins are often involved in the interaction with other proteins or with small molecules. Alternatively, they can provide sites for irreversible regulation of activity through proteolytic degradation $[63,64]$. The predicted effects of calcium (or manganese) ion binding are also interesting. Dynein light chains dimerise through a $\beta$-sheet structure which stretches across the two monomers. In 
FhCaBP3, calcium ion binding is predicted to disrupt the $\beta$-sheet structure of the dynein light chain-like domain which may disrupt, or reduce, the tendency of the protein to homodimerise (figure $2 \mathrm{~b}$ ). This is consistent with the observation that less protein-protein crosslinking and that the molecular mass as estimated by gel filtration doubled in the absence of calcium ions (figure 4).

Unlike FhCaBP4, binding of calcium ions to $\mathrm{FhCaBP} 3$ does not result in a measurably more hydrophobic protein surface. Nevertheless, it does induce conformational changes as indicated by both mobility shifts in native gel electrophoresis and intrinsic fluorescence changes. FhCaBP3 interacts with a number of drugs which bind to calmodulin and the related protein myosin regulatory light chain. Their mode of interaction appears to differ. TFP, W7 and PZQ alter the limited proteolysis pattern, suggesting alterations to the conformation of surfaceexposed loops; CPZ has no such effect. However, CPZ and TFP, but not PZQ, quench the fluorescence emission of FhCaBP3 suggesting that these compounds either bind in the vicinity of tryptophan residues or bind in a way which results in alterations to the protein structure in the environment of at least one tryptophan residue. Previously it has been suggested that PZQ antagonises voltage-gated calcium channels and it interacts with myosin regulatory light chain in schistosomes $[65,66]$. The observation that it interacts with $\mathrm{FhCaBP} 3$ adds to the list of potential targets of this drug.

The cellular roles of this group of proteins remain unclear. An early report on $S$. mansoni Sm20.8 indicated that the protein bound directly to a dynein light chain (SmDLC), presumably through the dynein light chain-like domain [25]. That the N- 
terminal domain can interact with calcium ions suggests that the proteins may have a role in sensing and responding to this ion in some signalling process. Given that dyneins function as microtubule motor proteins, disruption of these signalling pathways is likely to be detrimental to trematodes in a manner similar to that seen with benzimidazoles or tubulozole $\mathrm{C}$ [67]. Thus, selective antagonism of members of this family may offer a realistic and novel therapeutic approach to the treatment of fasciolisis and other trematode infections. Furthermore, the different biochemical properties of family members suggest that they have discrete functional roles within the organism. Determining these roles should be a key aim of further research in this area. 


\section{References}

[1] M.J. Berridge, P. Lipp, M.D. Bootman, The versatility and universality of calcium signalling, Nat.Rev.Mol.Cell Biol. 1 (2000) 11-21.

[2] Y.S. Babu, J.S. Sack, T.J. Greenhough, C.E. Bugg, A.R. Means, W.J. Cook, Three-dimensional structure of calmodulin, Nature 315 (1985) 37-40.

[3] Y.S. Babu, C.E. Bugg, W.J. Cook, Structure of calmodulin refined at $2.2 \mathrm{~A}$ resolution, J.Mol.Biol. 204 (1988) 191-204.

[4] H. Kuboniwa, N. Tjandra, S. Grzesiek, H. Ren, C.B. Klee, A. Bax, Solution structure of calcium-free calmodulin, Nat.Struct.Biol. 2 (1995) 768-776.

[5] M. Zhang, T. Tanaka, M. Ikura, Calcium-induced conformational transition revealed by the solution structure of apo calmodulin, Nat.Struct.Biol. 2 (1995) 758767.

[6] M. Zhang, T. Yuan, Molecular mechanisms of calmodulin's functional versatility, Biochem.Cell Biol. 76 (1998) 313-323.

[7] R. Gopalakrishna, W.B. Anderson, The effects of chemical modification of calmodulin on $\mathrm{Ca}^{2+}$-induced exposure of a hydrophobic region. Separation of active and inactive forms of calmodulin, Biochim.Biophys.Acta 844 (1985) 265-269. [8] W.J. Cook, L.J. Walter, M.R. Walter, Drug binding by calmodulin: crystal structure of a calmodulin-trifluoperazine complex, Biochemistry 33 (1994) 1525915265.

[9] M. Vandonselaar, R.A. Hickie, J.W. Quail, L.T. Delbaere, Trifluoperazineinduced conformational change in $\mathrm{Ca}^{2+}$-calmodulin, Nat.Struct.Biol. 1 (1994) 795801. 
[10] N. Matsushima, N. Hayashi, Y. Jinbo, Y. Izumi, $\mathrm{Ca}^{2+}$-bound calmodulin forms a compact globular structure on binding four trifluoperazine molecules in solution, Biochem.J. 347 (2000) 211-215.

[11] A.S. Taft, T.P. Yoshino, Cloning and functional characterization of two calmodulin genes during larval development in the parasitic flatworm Schistosoma mansoni, J.Parasitol. 97 (2011) 72-81.

[12] S.L. Russell, N.V. McFerran, E.M. Hoey, A. Trudgett, D.J. Timson, Characterisation of two calmodulin-like proteins from the liver fluke, Fasciola hepatica, Biol.Chem. 388 (2007) 593-599.

[13] S.L. Russell, N.V. McFerran, C.M. Moore, Y. Tsang, P. Glass, E.M. Hoey, A. Trudgett, D.J. Timson, A novel calmodulin-like protein from the liver fluke, Fasciola hepatica, Biochimie 94 (2012) 2397-2405.

[14] F.G. Abath, E.M. Xavier, S.M. Montenegro, R.P. Werkhauser, Partial molecular characterization of Sm8, a tegumental antigen of Schistosoma mansoni, Mem.Inst.Oswaldo Cruz 97 Suppl 1 (2002) 91-93.

[15] S. Hu, P. Law, Z. Lv, Z. Wu, M.C. Fung, Molecular characterization of a calcium-binding protein SjCa8 from Schistosoma japonicum, Parasitol.Res. 103 (2008) 1047-1053.

[16] H. Fraga, T.Q. Faria, F. Pinto, A. Almeida, R.M. Brito, A.M. Damas, FH8--a small EF-hand protein from Fasciola hepatica, FEBS J. 277 (2010) 5072-5085. [17] S. Vichasri-Grams, P. Subpipattana, P. Sobhon, V. Viyanant, R. Grams, An analysis of the calcium-binding protein 1 of Fasciola gigantica with a comparison to its homologs in the phylum Platyhelminthes, Mol.Biochem.Parasitol. 146 (2006) 1023. 
[18] P. Subpipattana, R. Grams, S. Vichasri-Grams, Analysis of a calcium-binding EF-hand protein family in Fasciola gigantica, Exp.Parasitol. 130 (2012) 364-373.

[19] G.J. Waine, M.M. Becker, J.C. Scott, B.H. Kalinna, W. Yang, D.P. McManus, Purification of a recombinant Schistosoma japonicum antigen homologous to the 22$\mathrm{kDa}$ membrane-associated antigen of $S$. mansoni, a putative vaccine candidate against schistosomiasis, Gene 142 (1994) 259-263.

[20] L.D. Stein, J.R. David, Cloning of a developmentally regulated tegument antigen of Schistosoma mansoni, Mol.Biochem.Parasitol. 20 (1986) 253-264.

[21] Y. Huang, Z. Zhou, X. Hu, Q. Wei, J. Xu, Z. Wu, X. Yu, A novel tegumental protein $31.8 \mathrm{kDa}$ of Clonorchis sinensis: sequence analysis, expression, and immunolocalization, Parasitol.Res. 102 (2007) 77-81.

[22] Y.J. Kim, W.G. Yoo, M.R. Lee, D.W. Kim, W.J. Lee, J.M. Kang, B.K. Na, J.W. $\mathrm{Ju}$, Identification and characterization of a novel 21.6-kDa tegumental protein from Clonorchis sinensis, Parasitol.Res. (2011)

[23] C.M. Fitzsimmons, T.J. Stewart, K.F. Hoffmann, J.L. Grogan, M. Yazdanbakhsh, D.W. Dunne, Human IgE response to the Schistosoma haematobium $22.6 \mathrm{kDa}$ antigen, Parasite Immunol. 26 (2004) 371-376.

[24] G. Senawong, T. Laha, A. Loukas, P.J. Brindley, B. Sripa, Cloning, expression, and characterization of a novel Opisthorchis viverrini calcium-binding EF-hand protein, Parasitol.Int. 61 (2012) 94-100.

[25] K.F. Hoffmann, M. Strand, Molecular characterization of a 20.8-kDa

Schistosoma mansoni antigen. Sequence similarity to tegumental associated antigens and dynein light chains, J.Biol.Chem. 272 (1997) 14509-14515.

[26] D.O. Lopes, L.F. Paiva, M.A. Martins, F.C. Cardoso, M.A. Rajao, J.M. Pinho, M.V. Caliari, R. Correa-Oliveira, S.M. Mello, L.C. Leite, S.C. Oliveira, Sm21.6 a 
novel EF-hand family protein member located on the surface of Schistosoma mansoni adult worm that failed to induce protection against challenge infection but reduced liver pathology, Vaccine 27 (2009) 4127-4135.

[27] P. Francis, Q. Bickle, Cloning of a 21.7-kDa vaccine-dominant antigen gene of Schistosoma mansoni reveals an EF hand-like motif, Mol.Biochem.Parasitol. 50 (1992) 215-224.

[28] C.M. Fitzsimmons, F.M. Jones, A. Stearn, I.W. Chalmers, K.F. Hoffmann, J. Wawrzyniak, S. Wilson, N.B. Kabatereine, D.W. Dunne, The Schistosoma mansoni tegumental-allergen-like (TAL) protein family: influence of developmental expression on human IgE responses, PLoS Negl Trop.Dis. 6 (2012) e1593.

[29] A.D. Ruiz de Eguino, A. Machin, R. Casais, A.M. Castro, J.A. Boga, J.M. Martin-Alonso, F. Parra, Cloning and expression in Escherichia coli of a Fasciola hepatica gene encoding a calcium-binding protein, Mol.Biochem.Parasitol. 101 (1999) 13-21.

[30] M.L. Santiago, J.C. Hafalla, J.D. Kurtis, G.L. Aligui, P.M. Wiest, R.M. Olveda, G.R. Olds, D.W. Dunne, B.L. Ramirez, Identification of the Schistosoma japonicum 22.6-kDa antigen as a major target of the human IgE response: similarity of IgEbinding epitopes to allergen peptides, Int.Arch.Allergy Immunol. 117 (1998) 94-104. [31] C.M. Fitzsimmons, R. McBeath, S. Joseph, F.M. Jones, K. Walter, K.F. Hoffmann, H.C. Kariuki, J.K. Mwatha, G. Kimani, N.B. Kabatereine, B.J. Vennervald, J.H. Ouma, D.W. Dunne, Factors affecting human IgE and IgG responses to allergen-like Schistosoma mansoni antigens: Molecular structure and patterns of in vivo exposure, Int.Arch.Allergy Immunol. 142 (2007) 40-50.

[32] M. Webster, R. Correa-Oliveira, G. Gazzinelli, I.R. Viana, L.A. Fraga, A.M. Silveira, D.W. Dunne, Factors affecting high and low human IgE responses to 
schistosome worm antigens in an area of Brazil endemic for Schistosoma mansoni and hookworm, Am.J.Trop.Med.Hyg. 57 (1997) 487-494.

[33] D.J. Overend, F.L. Bowen, Resistance of Fasciola hepatica to triclabendazole, Aust.Vet.J. 72 (1995) 275-276.

[34] G.B. Mitchell, L. Maris, M.A. Bonniwell, Triclabendazole-resistant liver fluke in Scottish sheep, Vet.Rec. 143 (1998) 399.

[35] I. Thomas, G.C. Coles, K. Duffus, Triclabendazole-resistant Fasciola hepatica in southwest Wales, Vet.Rec. 146 (2000) 200.

[36] M.A. Alvarez-Sanchez, R.C. Mainar-Jaime, J. Perez-Garcia, F.A. RojoVazquez, Resistance of Fasciola hepatica to triclabendazole and albendazole in sheep in Spain, Vet.Rec. 159 (2006) 424-425.

[37] I. Fairweather, Triclabendazole: new skills to unravel an old(ish) enigma, J.Helminthol. 79 (2005) 227-234.

[38] I. Fairweather, Triclabendazole progress report, 2005-2009: an advancement of learning? J.Helminthol. 83 (2009) 139-150.

[39] G.P. Brennan, I. Fairweather, A. Trudgett, E. Hoey, McCoy, M. McConville, M. Meaney, M. Robinson, N. McFerran, L. Ryan, C. Lanusse, L. Mottier, L. Alvarez, H. Solana, G. Virkel, P.M. Brophy, Understanding triclabendazole resistance, Exp.Mol.Pathol. 82 (2007) 104-109.

[40] R. Orr, R. Kinkead, R. Newman, L. Anderson, E.M. Hoey, A. Trudgett, D.J. Timson, FhCaBP4: a Fasciola hepatica calcium-binding protein with EF-hand and dynein light chain domains, Parasitol.Res. 111 (2012) 1707-1713.

[41] L.A. Ryan, E. Hoey, A. Trudgett, I. Fairweather, M. Fuchs, M.W. Robinson, E. Chambers, D.J. Timson, E. Ryan, T. Feltwell, A. Ivens, G. Bentley, D. Johnston, 
Fasciola hepatica expresses multiple $\alpha$ - and $\beta$-tubulin isotypes,

Mol.Biochem.Parasitol. 159 (2008) 73-78.

[42] M.M. Bradford, A rapid and sensitive method for the quantitation of microgram quantities of protein utilizing the principle of protein-dye binding, Anal.Biochem. 72 (1976) 248-254.

[43] J.D. Thompson, T.J. Gibson, D.G. Higgins, Multiple sequence alignment using ClustalW and ClustalX, Curr.Protoc.Bioinformatics Chapter 2 (2002) Unit 2.3.

[44] R. Chenna, H. Sugawara, T. Koike, R. Lopez, T.J. Gibson, D.G. Higgins, J.D. Thompson, Multiple sequence alignment with the Clustal series of programs, Nucleic Acids Res. 31 (2003) 3497-3500.

[45] S. Kumar, M. Nei, J. Dudley, K. Tamura, MEGA: a biologist-centric software for evolutionary analysis of DNA and protein sequences, Brief Bioinform 9 (2008) 299-306.

[46] L.A. Kelley, M.J. Sternberg, Protein structure prediction on the Web: a case study using the Phyre server, Nat.Protoc. 4 (2009) 363-371.

[47] E. Krieger, K. Joo, J. Lee, J. Lee, S. Raman, J. Thompson, M. Tyka, D. Baker, K. Karplus, Improving physical realism, stereochemistry, and side-chain accuracy in homology modeling: Four approaches that performed well in CASP8, Proteins 77 Suppl 9 (2009) 114-122.

[48] M.N. Wass, L.A. Kelley, M.J. Sternberg, 3DLigandSite: predicting ligandbinding sites using similar structures, Nucleic Acids Res. 38 (2010) W469-W473. [49] S. Kim, D.N. Cullis, L.A. Feig, J.D. Baleja, Solution structure of the Reps1 EH domain and characterization of its binding to NPF target sequences, Biochemistry 40 (2001) 6776-6785. 
[50] R.A. Durst, B.R. Staples, Tris/tris-HCl: a standard buffer for use in the physiologic pH range, Clin.Chem. 18 (1972) 206-208.

[51] T.C. Laurent, J. Killander, A theory of gel filtration and its experimental verification, J.Chromatogr. A 14 (1964) 317-330.

[52] J.L. Gifford, M.P. Walsh, H.J. Vogel, Structures and metal-ion-binding properties of the Ca2+-binding helix-loop-helix EF-hand motifs, Biochem.J. 405 (2007) 199-221.

[53] J. Liang, S.R. Jaffrey, W. Guo, S.H. Snyder, J. Clardy, Structure of the PIN/LC8 dimer with a bound peptide, Nat.Struct.Biol. 6 (1999) 735-740.

[54] J. Fan, Q. Zhang, H. Tochio, M. Li, M. Zhang, Structural basis of diverse sequence-dependent target recognition by the $8 \mathrm{kDa}$ dynein light chain, J.Mol.Biol. 306 (2001) 97-108.

[55] K. Lai, A.C. Willis, L.J. Elsas, The biochemical role of glutamine 188 in human galactose-1-phosphate uridyltransferase, J.Biol.Chem. 274 (1999) 6559-6566.

[56] R. Cappai, S.L. Leck, D.J. Tew, N.A. Williamson, D.P. Smith, D. Galatis, R.A. Sharples, C.C. Curtain, F.E. Ali, R.A. Cherny, J.G. Culvenor, S.P. Bottomley, C.L. Masters, K.J. Barnham, A.F. Hill, Dopamine promotes $\alpha$-synuclein aggregation into SDS-resistant soluble oligomers via a distinct folding pathway, FASEB J. 19 (2005) 1377-1379.

[57] C.I. Seye, G.R. De Meyer, W. Martinet, M.W. Knaapen, H. Bult, A.G. Herman, M.M. Kockx, Upregulation and formation of SDS-resistant oligomers of the proapoptotic factor Bax in experimental atherosclerosis, Ann.N.Y.Acad.Sci. 1010 (2003) 738-741. 
[58] D. Devost, H.H. Zingg, Identification of dimeric and oligomeric complexes of the human oxytocin receptor by co-immunoprecipitation and bioluminescence resonance energy transfer, J.Mol.Endocrinol. 31 (2003) 461-471.

[59] J. Tao, H.Y. Wang, C.C. Malbon, Protein kinase A regulates AKAP250 (gravin) scaffold binding to the $\beta 2$-adrenergic receptor, EMBO J. 22 (2003) 6419-6429. [60] L. Stryer, The interaction of a naphthalene dye with apomyoglobin and apohemoglobin. A fluorescent probe of non-polar binding sites, J.Mol.Biol. 13 (1965) 482-495.

[61] D.C. LaPorte, B.M. Wierman, D.R. Storm, Calcium-induced exposure of a hydrophobic surface on calmodulin, Biochemistry 19 (1980) 3814-3819.

[62] C.G. Bunick, M.R. Nelson, S. Mangahas, M.J. Hunter, J.H. Sheehan, L.S.

Mizoue, G.J. Bunick, W.J. Chazin, Designing sequence to control protein function in an EF-hand protein, J.Am.Chem.Soc. 126 (2004) 5990-5998.

[63] H.J. Dyson, P.E. Wright, Intrinsically unstructured proteins and their functions, Nat.Rev.Mol.Cell Biol. 6 (2005) 197-208.

[64] P. Tompa, The interplay between structure and function in intrinsically unstructured proteins, FEBS Lett. 579 (2005) 3346-3354.

[65] R.M. Greenberg, Are $\mathrm{Ca}^{2+}$ channels targets of praziquantel action? Int.J.Parasitol. $35(2005)$ 1-9.

[66] M. Gnanasekar, A.M. Salunkhe, A.K. Mallia, Y.X. He, R. Kalyanasundaram, Praziquantel affects the regulatory myosin light chain of Schistosoma mansoni, Antimicrob.Agents Chemother. 53 (2009) 1054-1060.

[67] M.W. Robinson, A. Trudgett, E.M. Hoey, I. Fairweather, The effect of the microtubule inhibitor tubulozole-C on the tegument of triclabendazole-susceptible and triclabendazole-resistant Fasciola hepatica, Parasitol.Res. 91 (2003) 117-129. 


\section{Figure legends}

Figure 1: Sequence of FhCaBP3 and its analysis (a) The amino acid sequence of FhCaBP3 with the EF-hands underlined and the potential calcium coordinating residues shown in bold. (b) An UPGMA tree showing the similarities of sequences of selected trematode proteins which share the same domain organisation as FhCaBP3. Figures at the nodes give the percentage level of bootstrap support for the node after 1000 reiterations. Accession numbers: CsTegAnt (GAA56892); OvCaBP (no accession number assigned [24]); CsTegu21.6 (AEI69651); FhCaBP4 (GAA56892); FgCABP4 (AEX92829); FgCaBP3 (AEX92828); FgCaBP2 (no accession number assigned [18]); FH22 (CAA06036); FgCaBP1 (AAZ20312); Sm21.7 or SmTAL2 (P32070); SmTAL12 (CCE94320); Sj22.6 (AAB52407); Sm22.6 or SmTAL1 (AAA29922); Sh22.6 (AAW49250); Sm21.6 or SmTAL8 (ACL54849); SmTAL13 (CCE94321); SmTAL7 (CCE94316); SmTAL6 (CCE94315); SmTAL4 (ACN82431); Sm20.8 or SmTAL3 (AAC79130); SmTAL11 (CCE94319); SmTAL5 (CCE94314); SmTAL9 (CCE94317); SmTAL10 (CCE94318). (Cs, Clonorchis sinenis; Ov, Opisthorchis viverrini; Fg, Fasciola gigantica; Fh, Fasciola hepatica; Sm, Schistosoma mansoni; $\mathrm{Sj}$, Schistosoma japonicum; Sh, Schistosoma haematobium.)

Figure 2: Predicted structure of FhCaBP3 (a) Modelled structure of FhCaBP3 in the absence of a bound divalent cation. The $\mathrm{N}$ - and $\mathrm{C}$-termini are indicated by $\mathrm{N}$ and $\mathrm{C}$ respectively. (b) Modelled structure of $\mathrm{FhCaBP} 3$ in the presence of a calcium ion bound at the second EF-hand (shown as a sphere). Note the loss of the $\beta$-sheet structure in the C-terminal dynein light chain-like domain. (c) The structure of the first EF-hand domain showing the potential ion coordinating residues. (d) The structure of the second EF-hand binding domain with a calcium ion (sphere) 
coordinated. Structural representations in (a)-(d) were made using PyMol (www.pymol.org). (e) A plot of the polypeptide backbone flexibility (estimated as described in Materials and Methods) against residue number.

Figure 3: Expression and purification of FhCaBP3 SDS-PAGE (10\%) showing the expression and purification of recombinant FhCaBP3. M, molecular mass markers (sizes in $\mathrm{kDa}$ are shown to the left of the gel); $\mathrm{U}$, extract from cells prior to induction; I, extract from cells $2 \mathrm{~h}$ after induction; $\mathrm{S}$, soluble material following sonication of the cells; F, material which flowed through the column; W, material which was removed from the column by washing with buffer A; E1, E2 and E3, the first, second and third elutions with buffer B.

\section{Figure 4: Dimerisation of FhCaBP3 is promoted by the absence of calcium ions}

(a) SDS-PAGE (10\%) showing the crosslinking of FhCaBP3 $(35 \mu \mathrm{M})$ with $\mathrm{BS}^{3}$. M, molecular mass markers (sizes in $\mathrm{kDa}$ are shown to the left of the gel). For $\mathrm{Ca}^{2+}$, represents the presence of $1 \mathrm{mM}$ EGTA and + the presence of $1 \mathrm{mM}$ EGTA and 2 $\mathrm{mM}$ calcium chloride. For $\mathrm{BS}^{3},-$ represents the absence of the reagent, + the presence of $80 \mu \mathrm{M}$ and ++ the presence of $800 \mu \mathrm{M}$. (b) Analytical gel filtration elution profile of FhCaBP3 $(380 \mu \mathrm{M})$ in the presence of either $2 \mathrm{mM}$ calcium chloride (filled squares, $+\mathrm{Ca}^{2+}$ ) or 2 mM EGTA (open squares, $-\mathrm{Ca}^{2+}$ ).

Figure 5: Divalent ion binding by FhCaBP3 (a) FhCaBP3 (90 $\mu \mathrm{M})$ was resolved by $10 \%$ native polyacrylamide gel electrophoresis in the presence of $1 \mathrm{mM}$ EGTA, $1 \mathrm{mM}$ DTT and various ions (2 mM) as indicated. C, FhCaBP3 without added ions; E, FhCaBP3 in the presence of EGTA only. The altered mobility in the presence of 
calcium and manganese ions results from binding to these ions. (b) Fluorescence emission spectrum of FhCaBP3 $(2 \mu \mathrm{M})$ in the presence of $1 \mathrm{mM}$ EGTA $\left(-\mathrm{Ca}^{2+}\right)$ and in the presence of $1 \mathrm{mM}$ EGTA/2 $\mathrm{mM}$ calcium chloride $\left(+\mathrm{Ca}^{2+}\right)$. Each point represents the mean of three independent measurements.

Figure 6: Calmodulin antagonists interact with FhCaBP3 (a) SDS-PAGE (15\%) showing the effects of various drugs $(250 \mu \mathrm{M})$ on the digestion of FhCaBP3 $(40 \mu \mathrm{M})$ by chymotrypsin $(200 \mathrm{nM})$ in the presence of $2 \mathrm{mM}$ calcium chloride. M, molecular mass markers (sizes in $\mathrm{kDa}$ are shown to the left of the gel); U, undigested FhCaBP3; C, chymotrypsin only; -, FhCaBP3 digested in the absence of any drugs; DMSO, FhCaBP3 digested in the presence of 1\% (v/v) DMSO. (b) Fluorescence emission spectra of FhCaBP3 $(3 \mu \mathrm{M})$ in the presence of EGTA $(1 \mathrm{mM})$, calcium chloride (2 $\mathrm{mM})$, DTT $(1 \mathrm{mM})$ and various drugs $(130 \mu \mathrm{M})$. A control spectrum in the presence of $1 \%(\mathrm{v} / \mathrm{v})$ DMSO was also recorded. Each point represents the mean of three independent determinations and the error bars the standard deviations of these means. 
(a)

1

MATATRTSIK PKITFTKGQQ EPTVLSNVEQ MISLFLELDS NKDGSVTRDE

LVKFYESHKL NKSQIDEWMS RFDTDSDGKI TLEEFSKALG LDLDDLKMEK 150

VQLQNQRTSK KTEINVDGVE MLCTTMPVER QEVVVKKFKE LLQSVSGNEN

200

RMNEVNDKLK AFLDEKYGRI WQCITLTGSY WMRFSHEPFM SIQFKYQDKY 210

ICIAWRTHRV

(b)

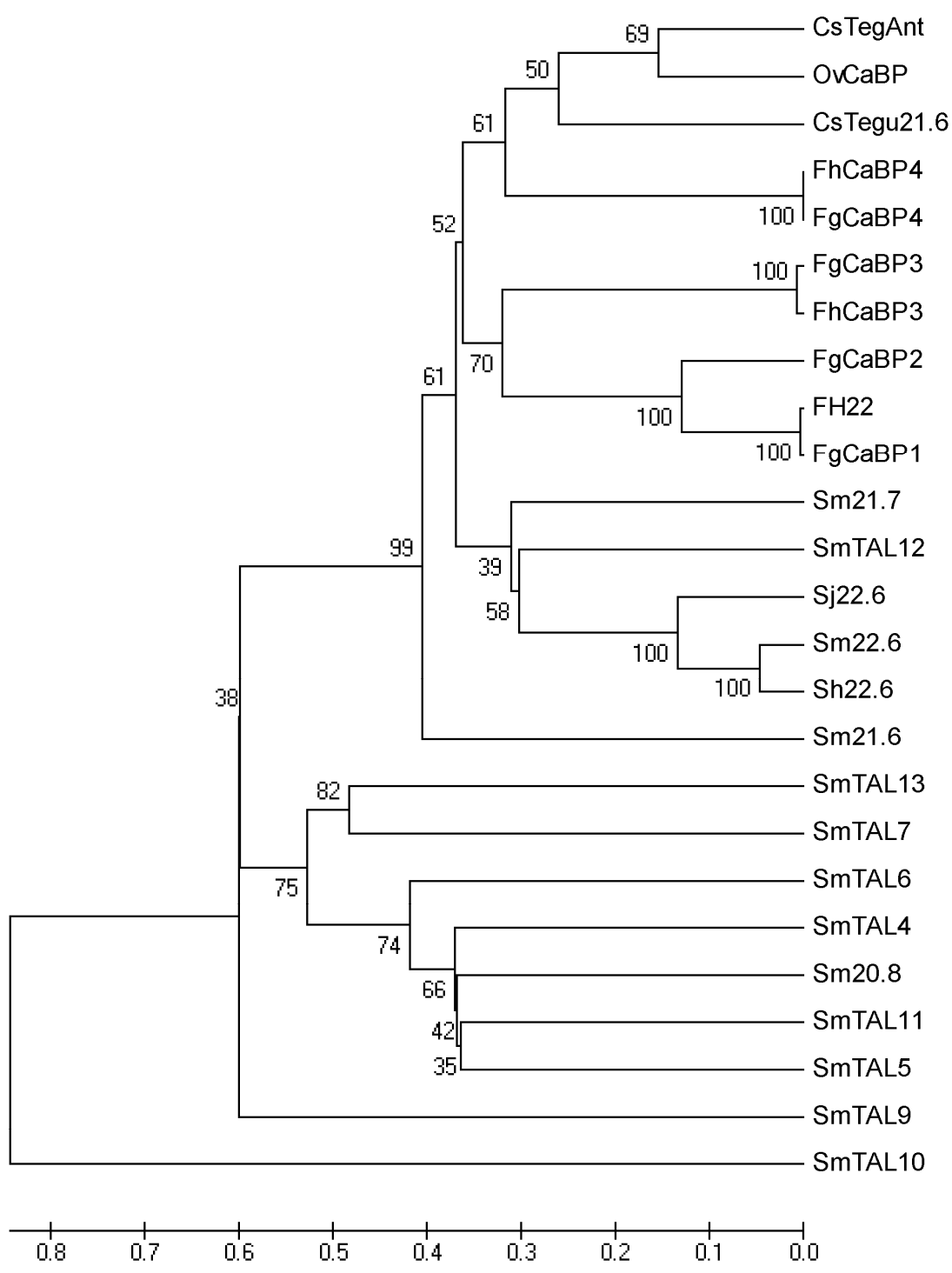


(a)

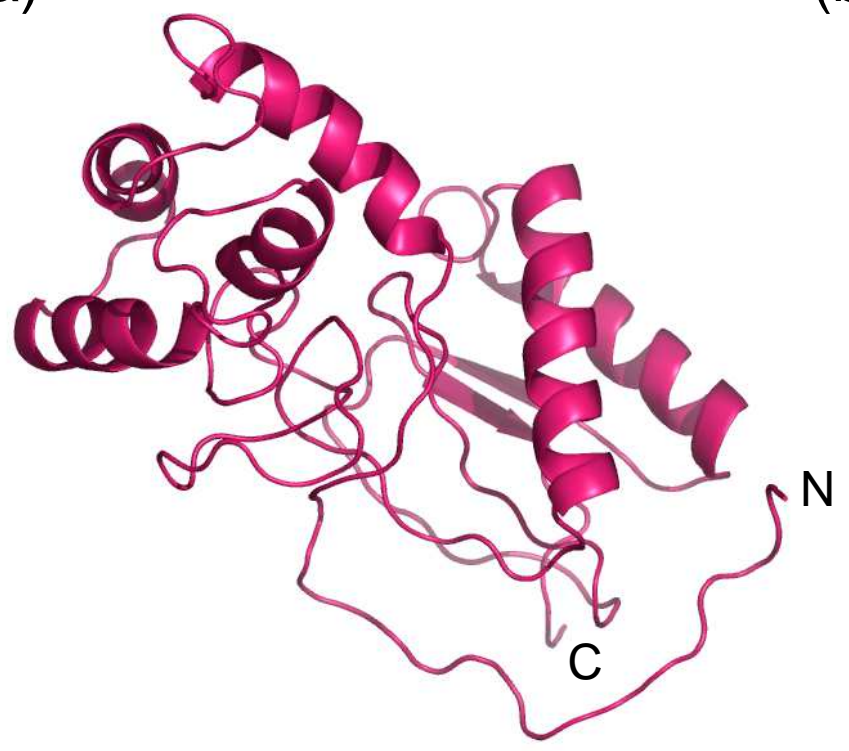

(b)

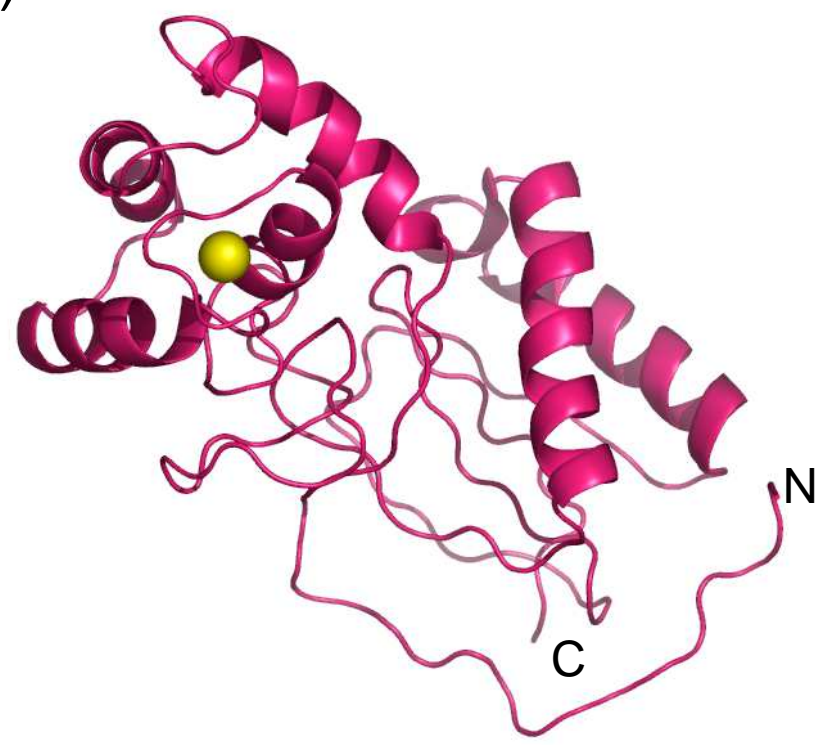

(c)

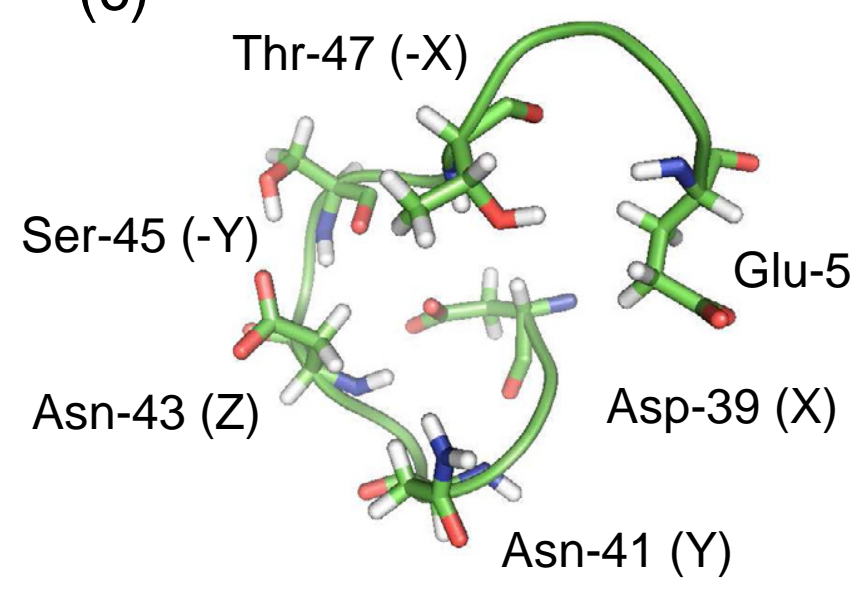

(d)

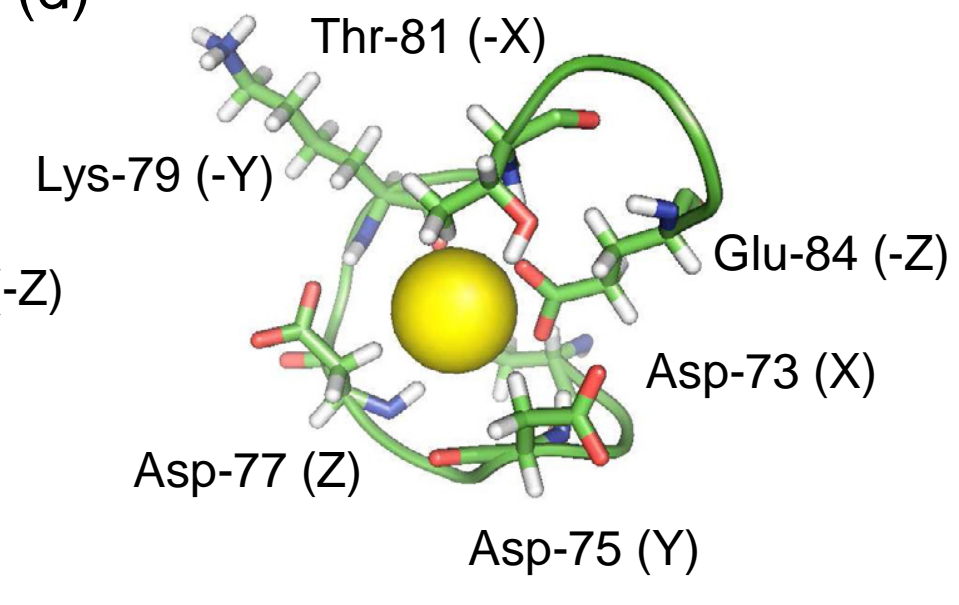

(e)

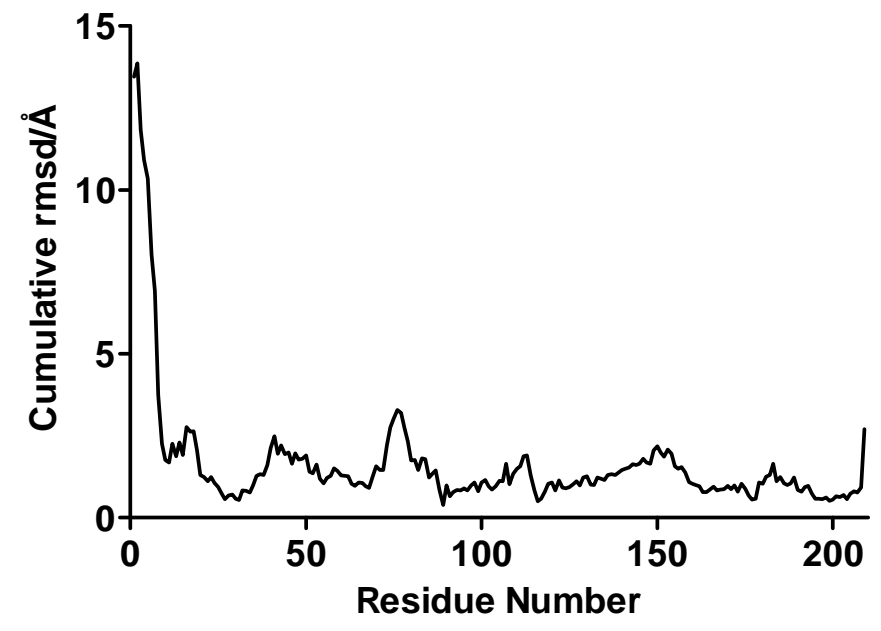


(a)

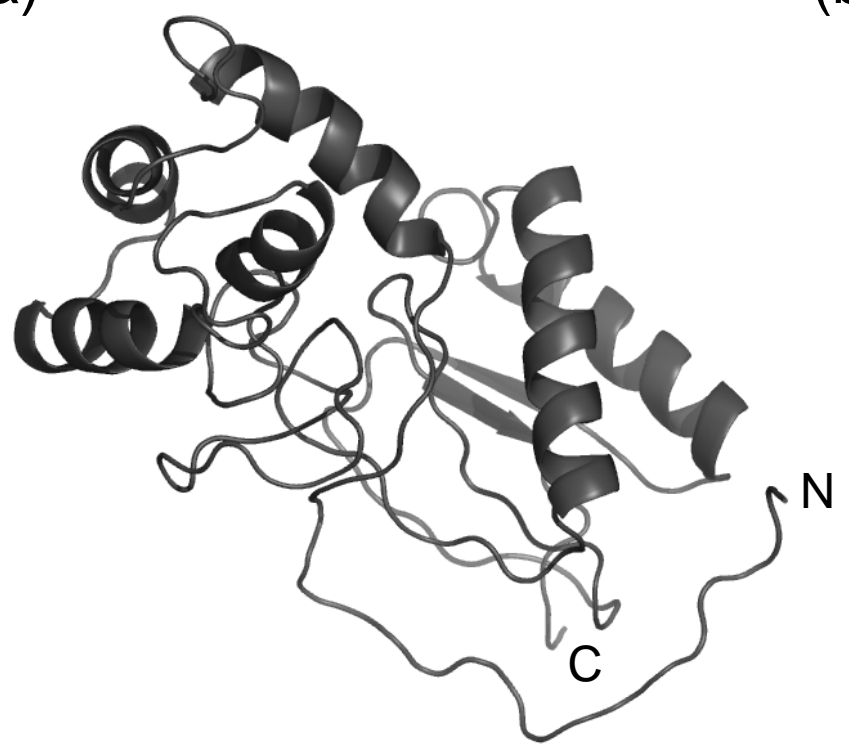

(b)

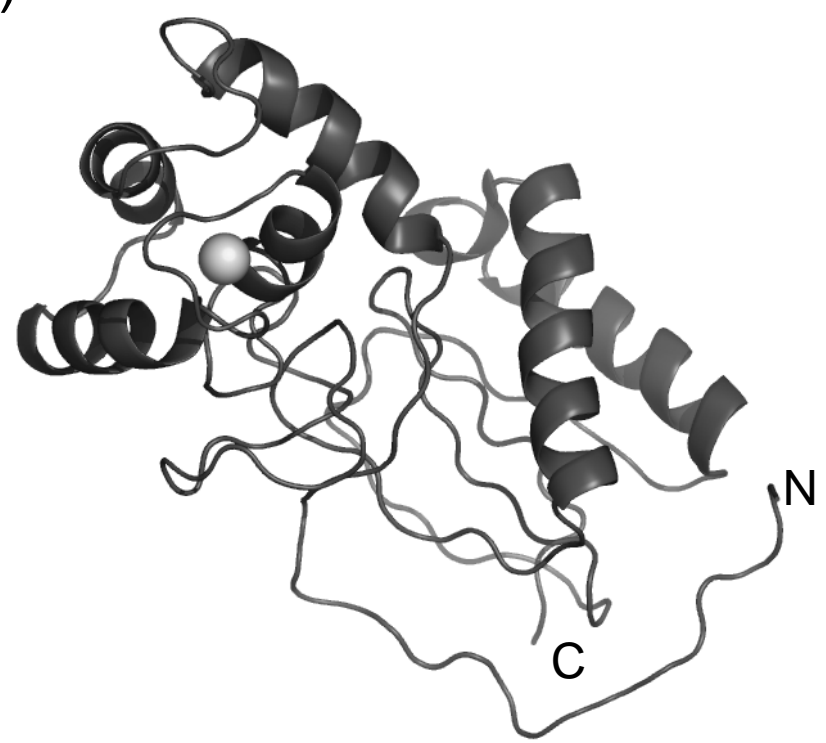

(c)

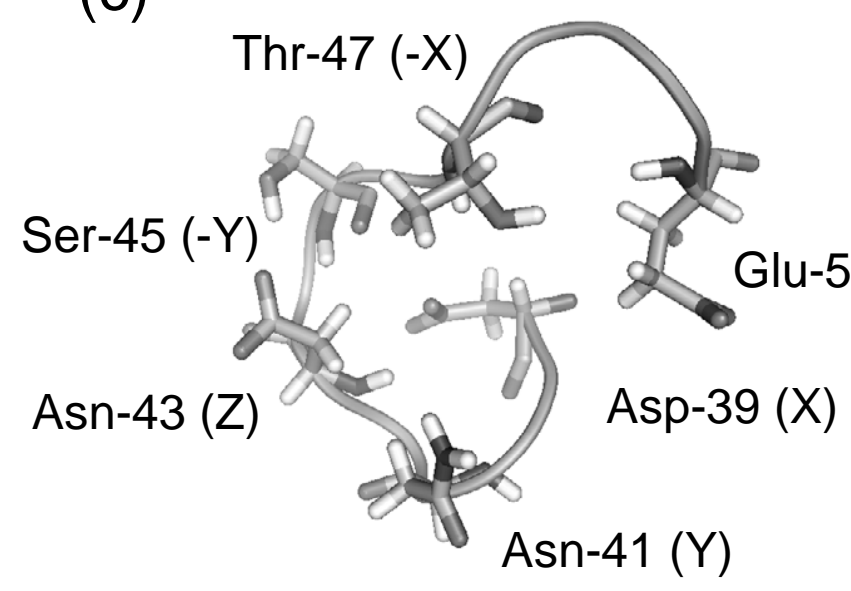

(e)

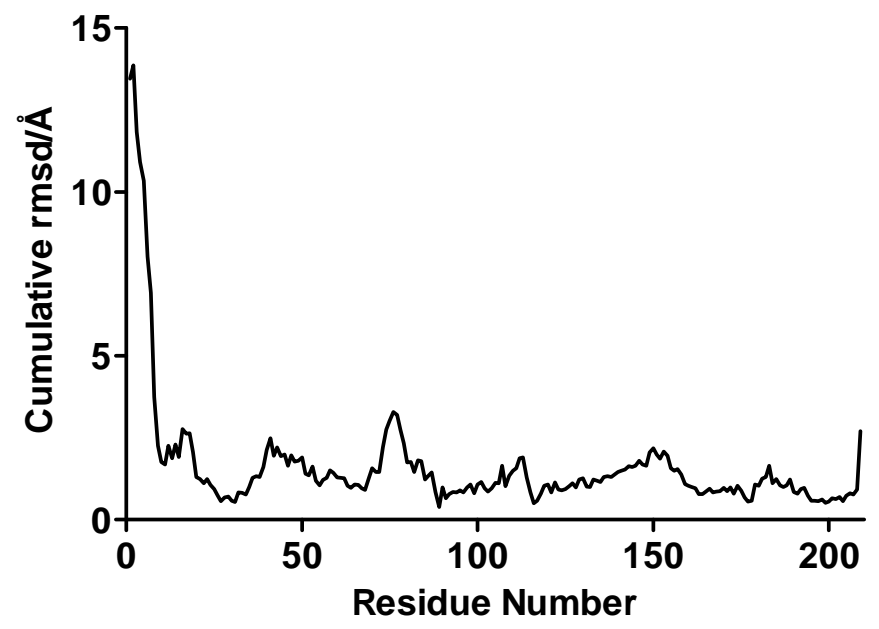

(d)

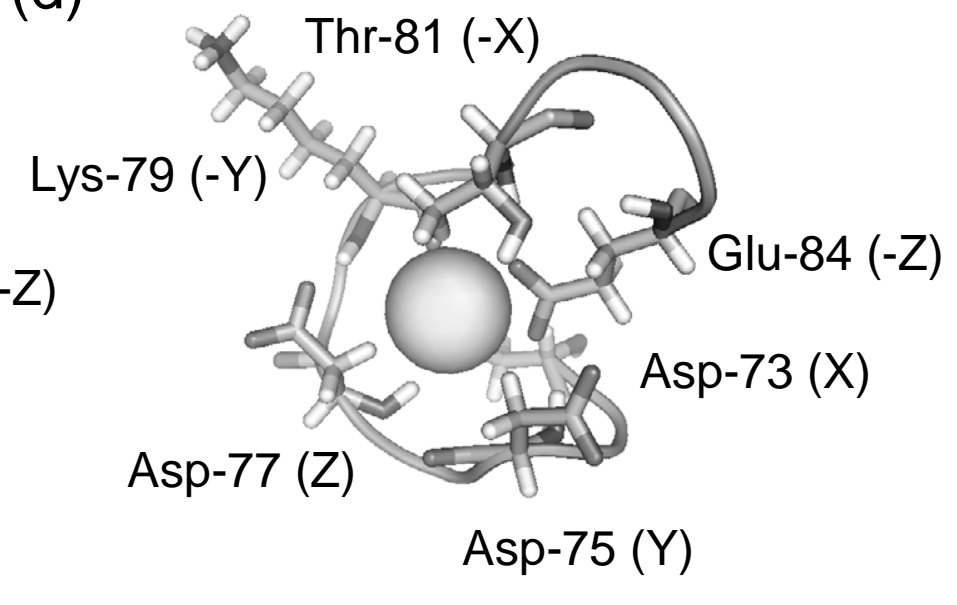




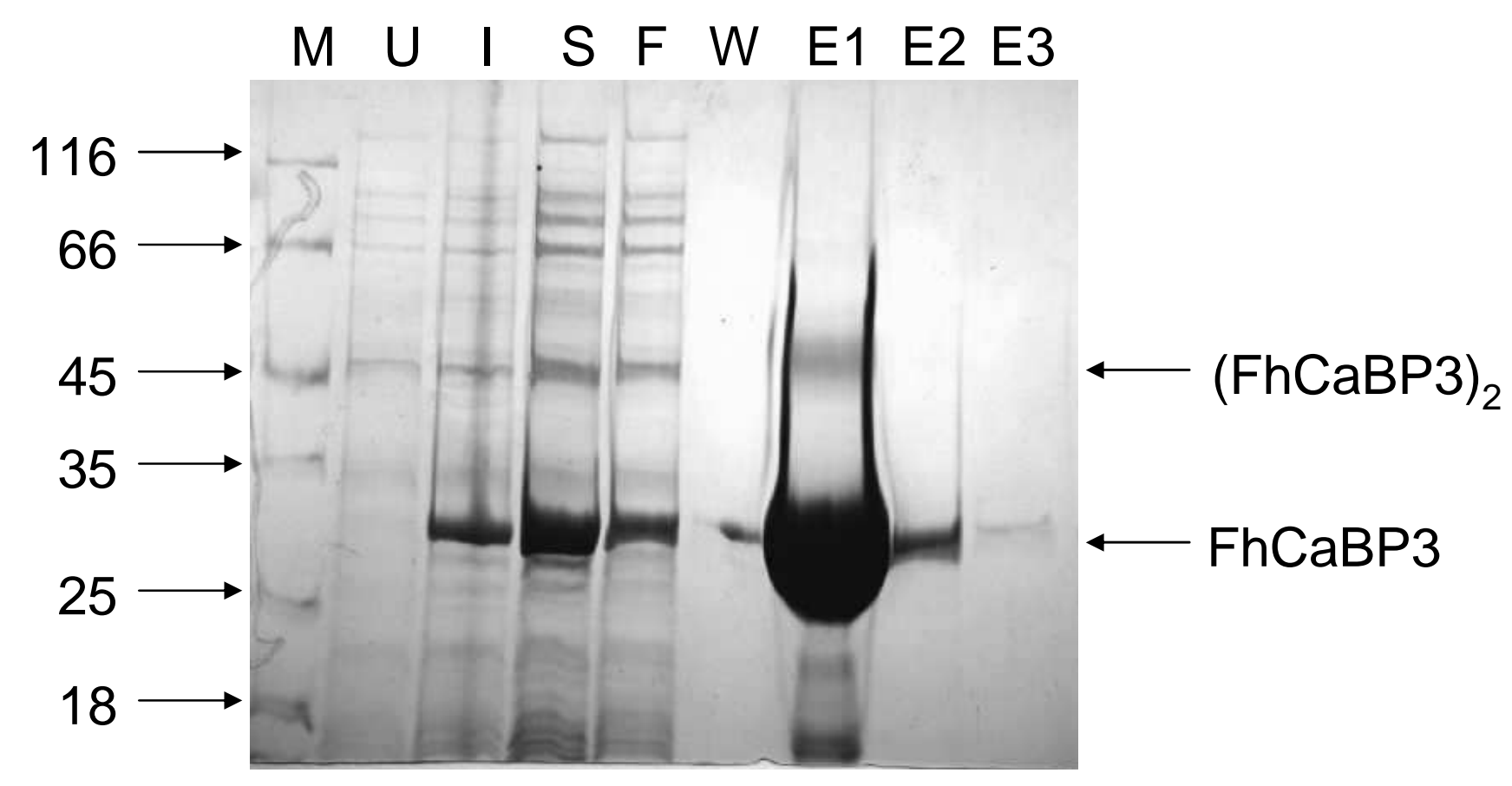


(a)

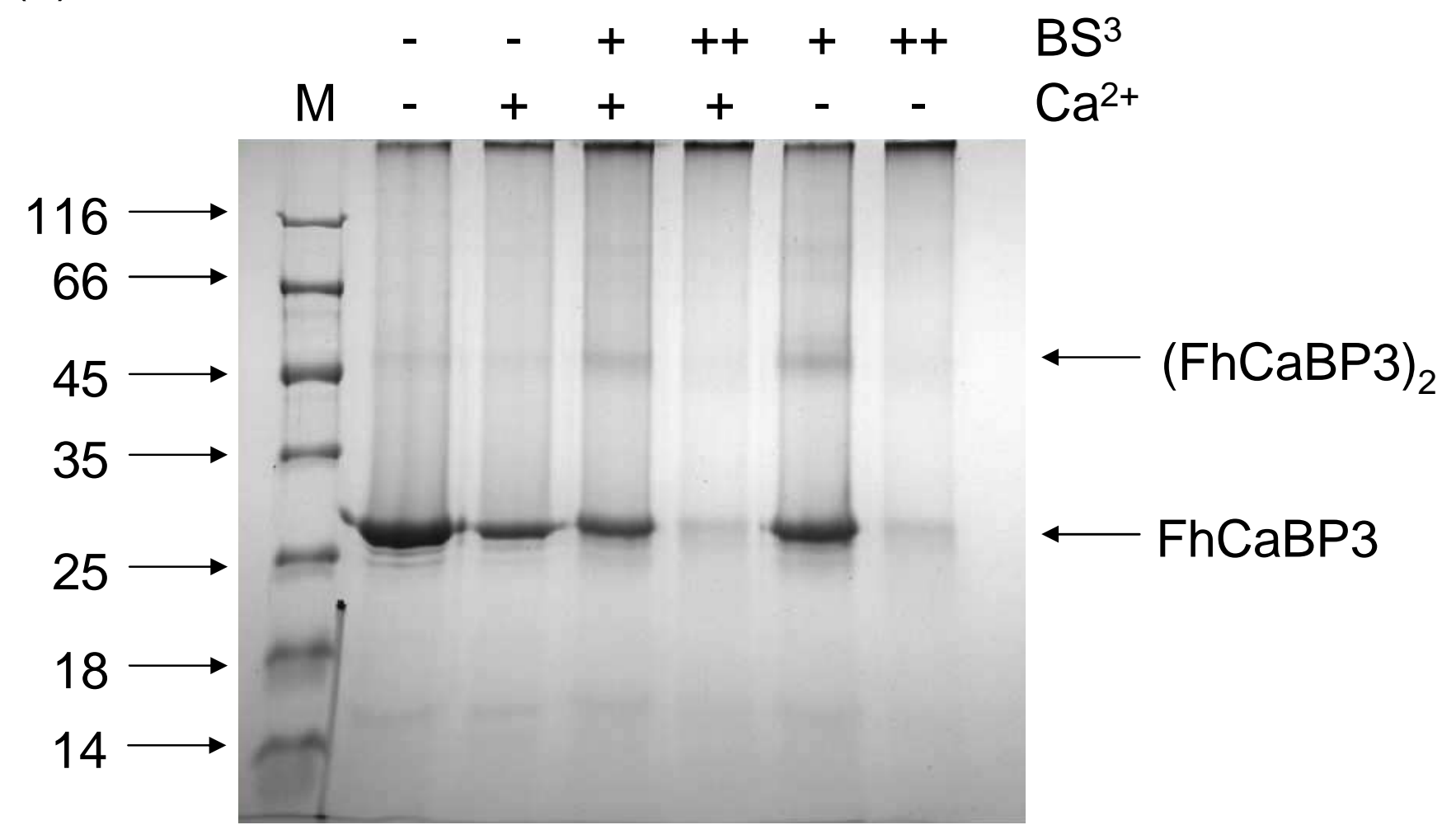

(b)

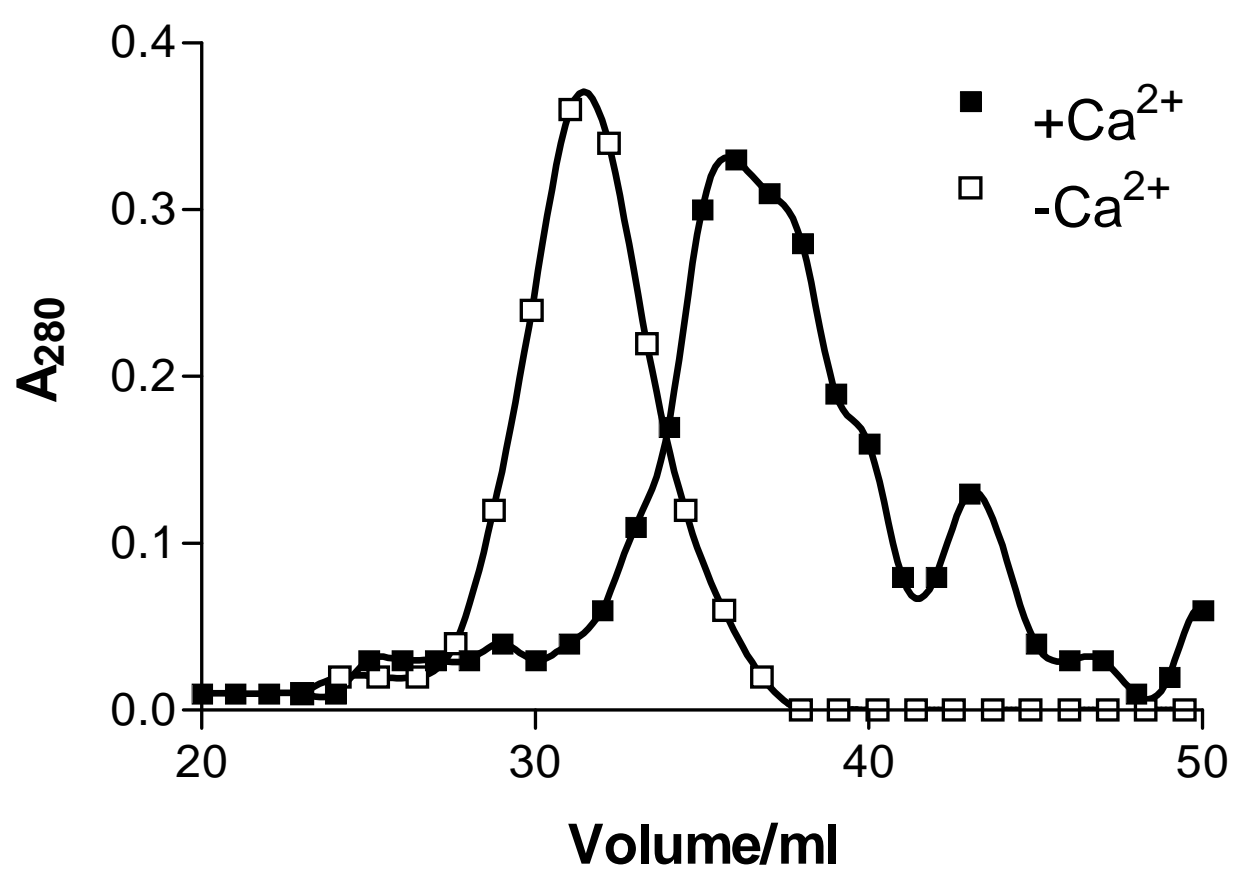


(a)
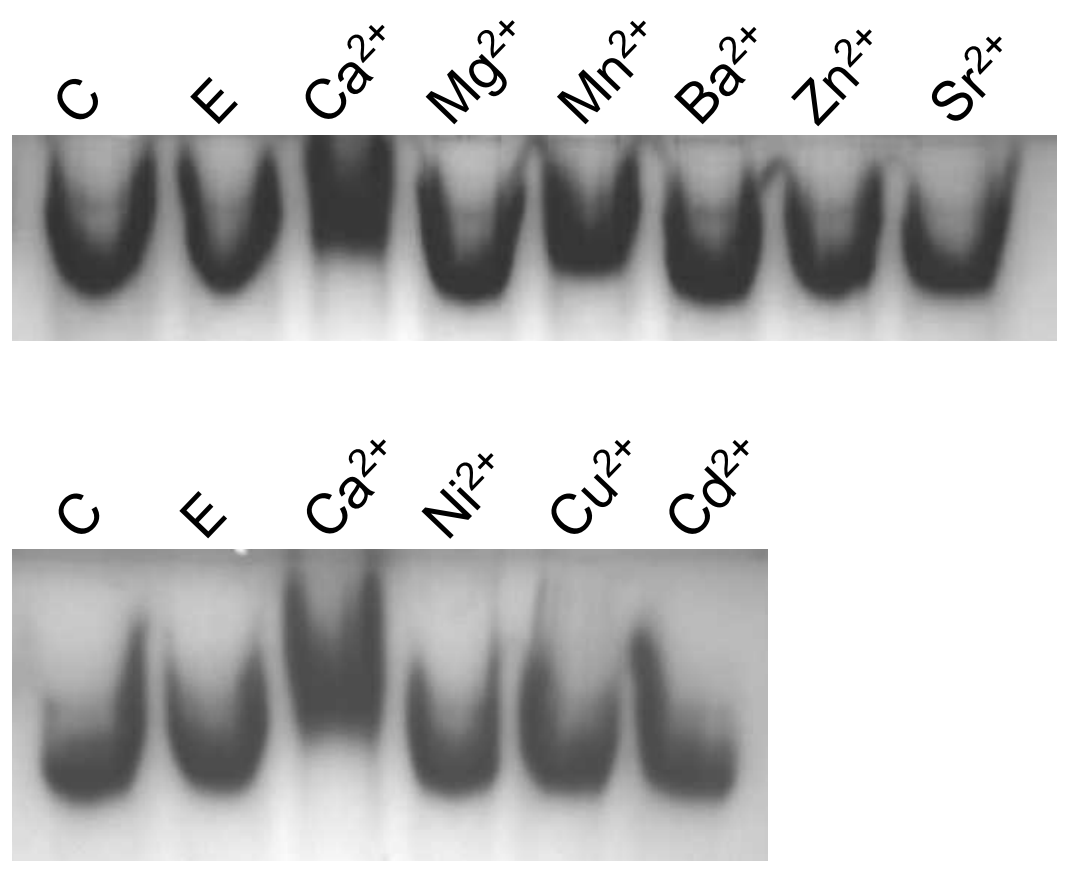

(b)

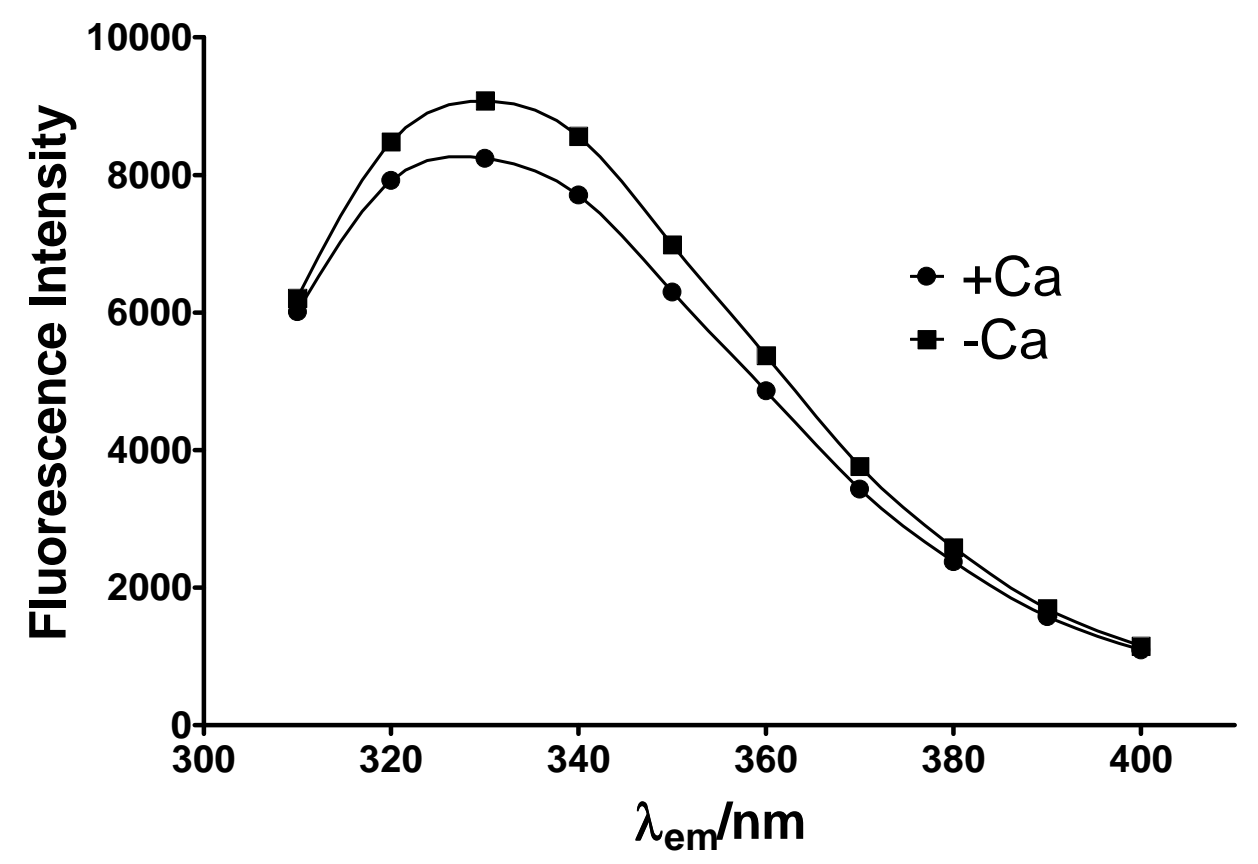


(a)

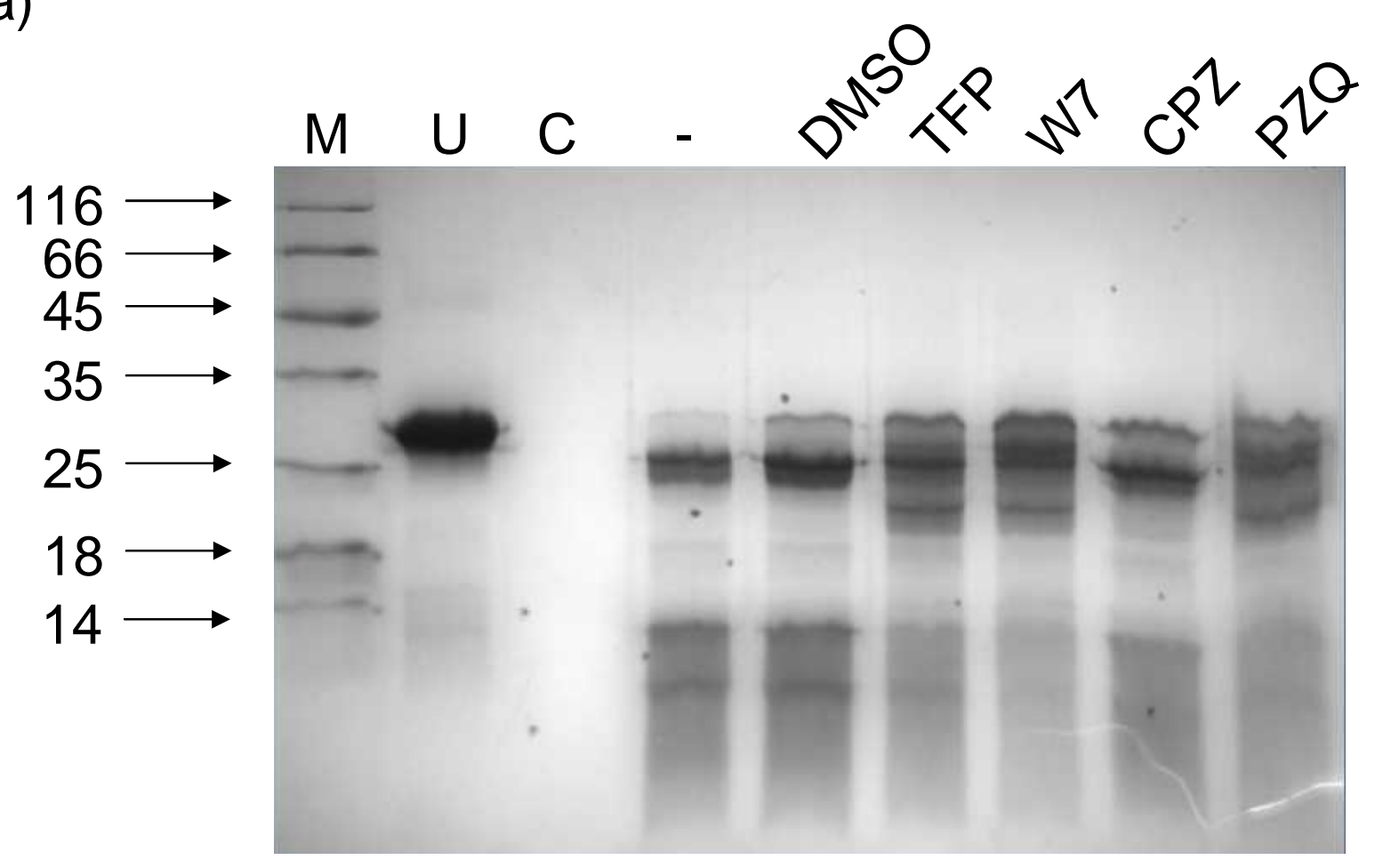

(b)

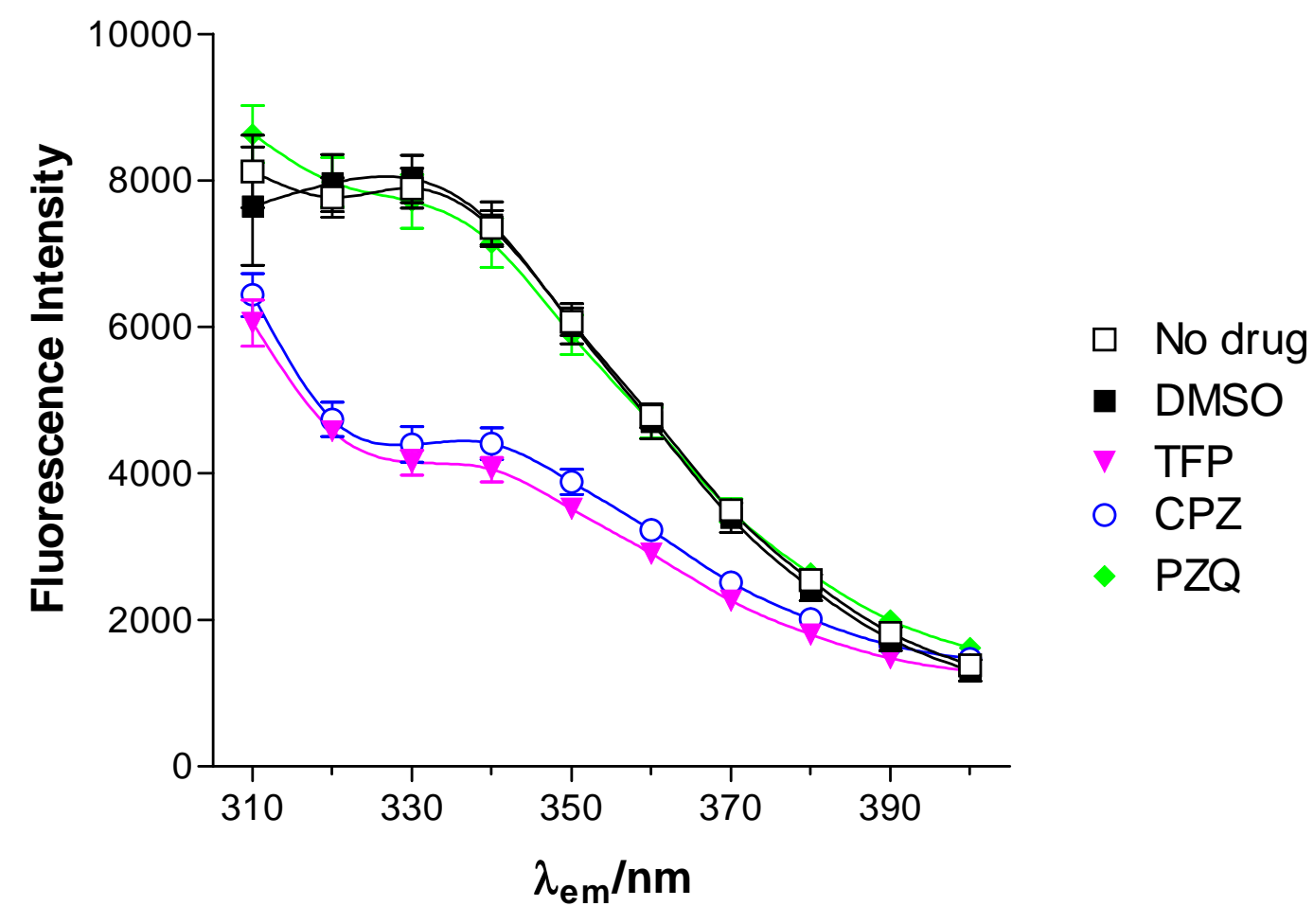


(a)

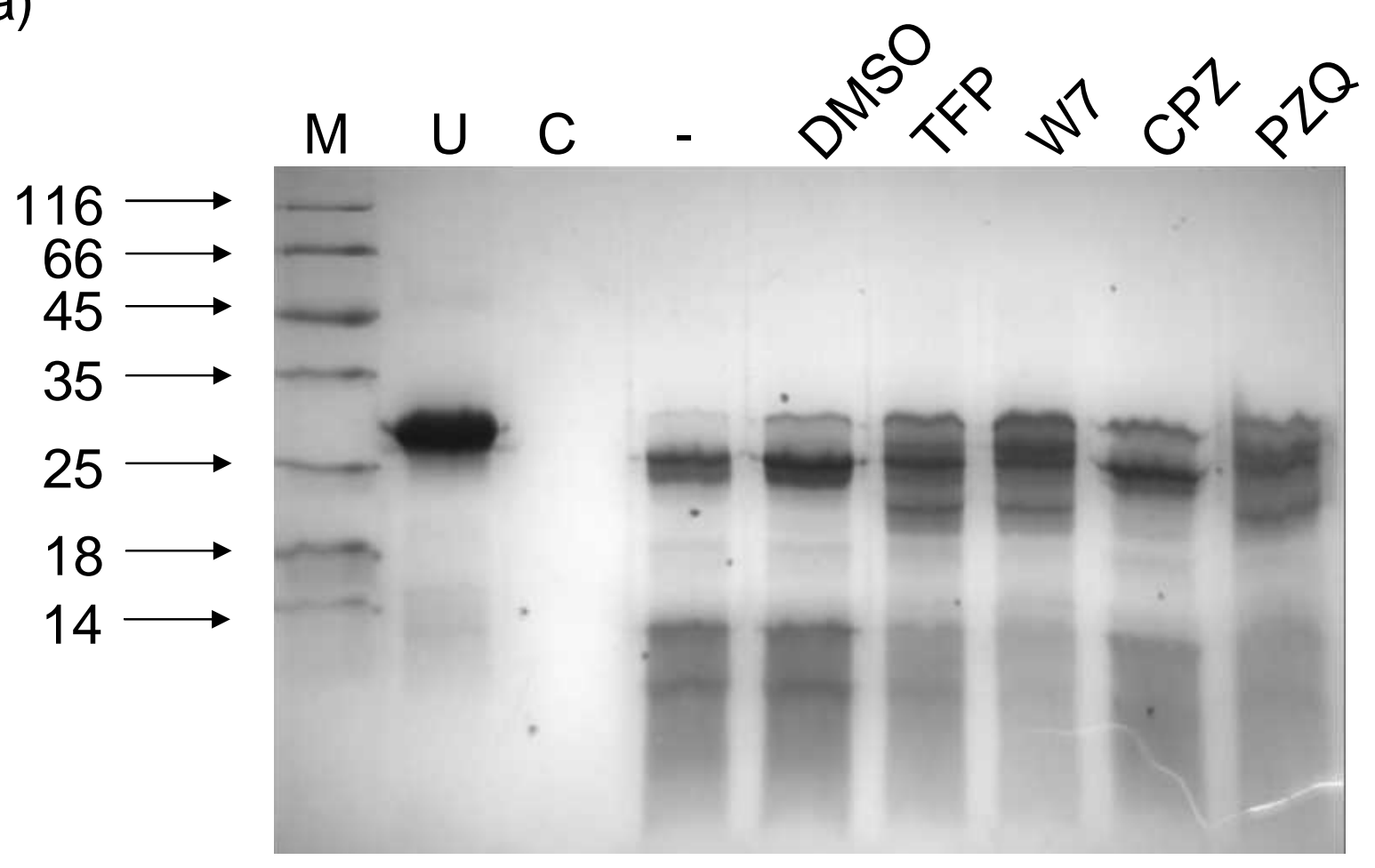

(b)

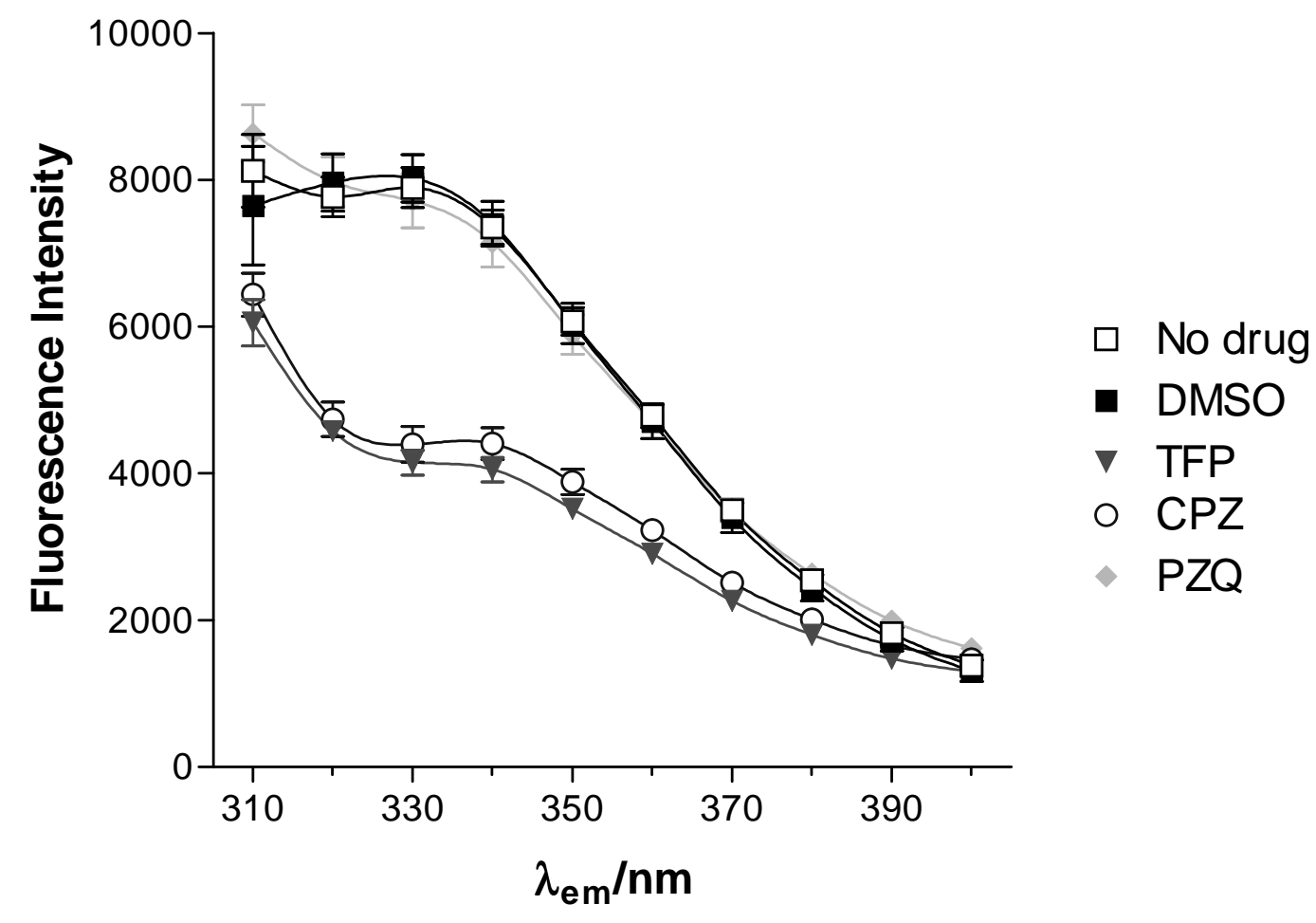

